\title{
Interface Shear of Ultra-High-Performance Concrete
}

\author{
by Scott Muzenski, Zachary B. Haber, and Benjamin Graybeal
}

\begin{abstract}
Due to its distinct mechanical properties, ultra-high-performance concrete (UHPC) behaves differently than conventional concrete when subjected to interface shear demands. The use of UHPC in primary structural elements, for which interface shear resistance can be an important structural response, is growing as UHPCclass materials become more readily available. Structural design provisions for the interface shear capacity of UHPC are needed. This research conducted 11 interface shear tests of monolithically cast UHPC and combined those results with other tests from the literature to develop a predictive model for UHPC. The interface shear capacity was studied by conducting tests with steel reinforcement of varying yield stress and reinforcement ratios at the interface. A predictive model was developed indicating that the total tensile resistance across the shear interface is a critical parameter in determining the peak shear resistance. This includes the tensile resistance of both the reinforcing steel and UHPC. Design guidance for the interface shear resistance of UHPC is also proposed.
\end{abstract}

Keywords: interface shear; structural design parameters; tensile behavior; ultra-high-performance concrete (UHPC).

\section{INTRODUCTION}

Ultra-high-performance concrete (UHPC) provides new opportunities to structural designers due to its mechanical and durability properties. UHPC is a strain-hardening, fiber-reinforced concrete with a compressive strength greater than $18 \mathrm{ksi}(124 \mathrm{MPa}) .{ }^{1}$ UHPC generally includes a high concentration of steel fiber reinforcement, which contributes to the novel tensile stress and strain responses as compared with other cement-based materials. The tensile cracking strength is greater than $0.72 \mathrm{ksi}(5 \mathrm{MPa})$ and the tensile cracking strength is sustained, via the discontinuous internal fiber reinforcement, through a tensile strain of at least $0.0025 .{ }^{1}$ The modulus of elasticity is usually within the range of 6000 to $8000 \mathrm{ksi}$ (41 to $55 \mathrm{GPa}){ }^{2}$

As with any novel structural material, the lack of UHPC-specific structural design specifications is limiting the use of the material. In lieu of such provisions, designers often look to code provisions intended for conventional concrete, but the code provisions are often not applicable due to inherent differences between UHPC and conventional concrete. To address the need for UHPC, the Federal Highway Administration (FHWA) has begun a multiyear effort, coordinated with the American Association of State Highway and Transportation Officials (AASHTO) Committee on Bridges and Structures, to develop the needed UHPC structural design guidance. Although tailored for bridge applications, the fundamentals of the design approach are applicable to a wide range of structural solutions outside of the realm of highway bridges. The proposed design process is founded on first principal approaches where key material-level performance characteristics are experimentally identified through appropriate testing and linked to the structural-level performance through structural mechanics, structural testing, and design models.

For example, the improved engineering properties of UHPC allow for girders to span greater distances using taller, more slender webs, and will allow for using more prestressing force and larger diameter prestressing strand. ${ }^{3-5}$ Furthermore, there is potential to significantly reduce the amount of web shear reinforcement or, in some cases, eliminate it completely by effectively using UHPC's inherent tensile stress and strain capacity. Girder designs that use the aforementioned characteristics would be subjected to higher interface (horizontal) shear stresses at web-to-flange interfaces.

Furthermore, there are other cases where interface shear is a critical design consideration. For example, some connection detail concepts that use UHPC for prefabricated bridge elements use horizontal shear-resisting lugs between girders and precast concrete decks, which are composed of UHPC. ${ }^{6}$ UHPC has some unique features in contrast to conventional concrete, such as fiber reinforcement and lack of coarse aggregate, that result in different interface shear behaviors. Given UHPC's unique features, interface shear provisions for conventional concretes are not appropriate for UHPC class materials, and thus, there is a need for a UHPC-specific interface shear capacity model and the associated design provisions.

\section{RESEARCH SIGNIFICANCE}

UHPC offers designers the opportunity to craft new solutions to existing structural engineering challenges. However, due to the lack of structural design provisions for UHPC, designers often rely on design provisions relevant to conventional concrete. As the use of UHPC in structural design is becoming a more attractive option, greater understanding of the UHPC structural response when subjected to specific demands is required. Due to the interest in UHPC in structural design, the Federal Highway Administration (FHWA) is coordinating with the AASHTO Committee on Bridges and Structures to draft a UHPC structural design guidance document. As part of the effort to draft the guidance document, the FHWA is performing research on the interface shear properties of UHPC. The research addresses a significant portion of the topic by analyzing how monolithically cast UHPC responds to shear at interfaces when used with

ACI Structural Journal, V. 119, No. 1, January 2022.

MS No. S-2021-072.R1, doi: 10.14359/51733008, received June 24, 2021, and reviewed under Institute publication policies. Copyright (C) 2022, American Concrete Institute. All rights reserved, including the making of copies unless permission is obtained from the copyright proprietors. Pertinent discussion including author's closure, if any, will be published ten months from this journal's date if the discussion is received within four months of the paper's print publication. 
reinforcement of varying yield strengths and varying reinforcement ratios.

\section{EXISTING INTERFACE SHEAR DESIGN PROVISIONS Historical perspective}

Interface shear design provisions are generally based on the "shear-friction theory." The theory was initially proposed by Birkeland and Birkeland to assess the shear resistance between concrete cast at different times. ${ }^{7}$ The theory assumes that a crack will form along the interface. The crack along the interface will have roughness; thus, when slippage occurs, the crack will be forced to widen. Reinforcement crossing the interface will thus be strained and will provide a clamping pressure on the interface, serving to resist the demand through friction between the two interface surfaces. The interface shear capacity is thus a function of the coefficient of friction between the surfaces and the clamping force provided by the reinforcing steel. The shear-friction theory is also applicable in structural members where cracks form along interfaces or discontinuities, such as the interface between a girder web and flange.

Early research used the clamping pressure (interface reinforcement ratio multiplied by interface reinforcement yield stress) as the basis for best fit curves and, eventually, design equations..$^{7-9}$ Early research also identified that in nonmonolithic scenarios, the roughness of the interface was a contributing factor. The roughness of the interface was represented as a friction factor, $\mu$, in design equations. The theory assumes that once a crack occurs at the interface, the two planes will begin to separate, and the reinforcement will eventually yield. The theory is the foundation for the current ACI $318-19^{10}$ interface shear provisions.

Researchers later began to expand upon the design equations by adding an additional term for the supplemental resistance offered by chemical cohesion of the cementitious matrix across the interface, as well as the aggregate interlock across the interface. The component of resistance is collectively referred to as cohesion. ${ }^{11}$ Cohesion has been shown to be influenced by compressive strength of the concrete, which led some researchers to include a concrete compressive strength term in interface shear resistance equations. ${ }^{12-16}$

Another factor that researchers have identified as contributing to interface shear resistance is the dowel action of the reinforcement. ${ }^{17-19}$ Dowel action results from the reinforcement providing flexural resistance as the crack at the interface opens and the two planes slip relative to one another. Although few researchers or design provisions account for the contribution of dowel action, it may play a significant part in the interface shear resistance, especially at higher strains and with stiffer concretes. The fib Model Code $2010^{20}$ considers the effects of dowel action in their design provisions.

\section{Conventional concrete}

The design of concrete members subjected to shear transfer at interfaces is incorporated into most modern design provisions. ACI $318-19^{10}$ states that the nominal interface shear strength is the shear friction reinforcement area multiplied by the yield strength of the reinforcement crossing the interface multiplied by a friction coefficient, as shown in Eq. (1); a full list of notations is provided in Appendix I. ${ }^{*}$ The equation for nominal interface shear strength is applicable when the reinforcement is perpendicular to the interface. Based on ACI $318-19,{ }^{10}$ the friction coefficient for a normalweight, monolithically placed concrete is 1.4 ; this factor is reduced for non-monolithic interfaces. Furthermore, the design equation provides upper limits based on the interface area, the concrete compressive strength, and the maximum design yield strength of the reinforcement (60 ksi [414 MPa]).

$$
V_{n}=\mu A_{s v} f_{y}
$$

AASHTO LRFD Bridge Design Specifications, 9th Edition $^{21}$ provides a similar equation based on the friction coefficient, but includes a few additional variables, as shown in Eq. (2); a full list of notations is provided in Appendix I. Here, the cohesion component is added to the resistance model, which is represented as a cohesion coefficient multiplied by the interface area $\left(c A_{c v}\right)$. The cohesion component represents non-friction-based resistance at the interface, such as cohesion and aggregate interlock. The cohesion coefficient, $c$, and friction coefficient, $\mu$, are 0.4 and 1.4, respectively, for normalweight, monolithically placed concrete; again, these values depend on the construction method used for the concrete at the interface. Similar to ACI, upper limits to the calculated resistance are provided and the maximum design yield strength or reinforcement may not exceed 60 ksi (414 MPa). The equation and variables used by AASHTO LRFD Bridge Design Specifications ${ }^{21}$ for normalweight, monolithically placed concrete were based on experimental data with concrete compressive strengths between 3.5 and $18.0 \mathrm{ksi}(24.1$ and $124.1 \mathrm{MPa})$.

$$
V_{n}=c A_{c v}+\mu\left(A_{s v} f_{y}+P_{c}\right)
$$

Other international structural design specifications provide similar design equations. Eurocode $2^{22}$ and CSA S6 $6^{23}$ consider resistance components similar to the AASHTO code provision. The $f i b$ Model Code $2010^{20}$ interface shear relationship, based on the work of Randl, ${ }^{18}$ considers the cohesion, friction, and dowel action contributions to interface shear resistance.

\section{UHPC-class materials}

UHPC has unique features, such as fiber reinforcement and lack of coarse aggregate, that are likely to change the interface shear behavior compared with conventional concrete. UHPCs exhibit sustained post-cracking tensile resistance, which would contribute to the clamping force across the interface. The lack of coarse aggregate would likely influence the contribution of aggregate interlock along the interface plane, which would impact both the cohesion and friction contributions to the interface shear resistance. The higher mechanical strength of the UHPC

\footnotetext{
"The Appendix is available at www.concrete.org/publications in PDF format, appended to the online version of the published paper. It is also available in hard copy from ACI headquarters for a fee equal to the cost of reproduction plus handling at the time of the request.
} 
might also lead to increased cohesion. Differences related to tensile properties, mechanical strength, and aggregate type and proportion, which in total are likely to increase the interface shear capacity of UHPCs compared with conventional concretes, would make existing conventional concrete provisions overly conservative and not applicable to UHPC. The French supplement to the Eurocode, which facilitates the design of UHPC structures, NF P18-710, ${ }^{24}$ allows for the shear resistance provided by the UHPC to be considered in the design for shear resistance at the interface between beam flanges and webs. However, little guidance is available for the UHPC resistance to interface shear within other design specifications.

\section{PREVIOUS RESEARCH ON UHPC INTERFACE SHEAR BEHAVIOR}

There is limited research on the interface shear behavior of monolithically cast UHPC and UHPC-to-UHPC cold joints, or on how the products of that research could be incorporated into design provisions. In general, studies have found that UHPC interface shear resistance exceeds that provided by conventional concrete, and thus, existing design provisions for conventional concrete are conservative when applied to UHPC. One of the earliest studies was performed by Crane, ${ }^{25}$ who conducted extensive physical testing, which included interface shear pushoff tests. The pushoff tests included monolithic UHPC and UHPC-to-UHPC cold joints. Crane proposed a friction coefficient of 4.5 and an intercept coefficient (often referred to as a cohesion coefficient, as previously discussed) of $2 \mathrm{ksi}(13.8 \mathrm{MPa})$ for monolithic UHPC; however, it was noted that the coefficients may only be applicable for clamping pressures up to $300 \mathrm{psi}(2.1 \mathrm{MPa})$ from the reinforcement because tests with higher reinforcement ratios had yet to be performed. Jang et al. ${ }^{26}$ performed research on the interface shear of monolithic UHPC, and on UHPC-to-UHPC cold joints with varying surface preparation. Here, it was found that the increased tensile resistance of UHPC at large tensile strains allowed for higher ductility along the interface. Wu et al. performed pushoff tests to determine the interface shear properties of UHPC. ${ }^{27}$ The pushoff tests included UHPC with varying fiber content and varying reinforcement ratios, and the researchers proposed relationships for interface shear behavior, which included fiber content as a parameter. However, the interface shear behavior relationships did not provide any input for specific tensile properties based on the varying fiber contents. Semendary and Svecova ${ }^{28}$ performed research to extract the material-level properties of UHPC to use in interface shear equations. The Semendary and Svecova research consisted of pullout tests, bi-shear tests, and slant-shear tests to estimate the cohesion and friction factors. ${ }^{28} \mathrm{Kim}$ et al. ${ }^{29}$ studied the interface shear properties of UHPC using dried and epoxied shear keys for connection elements of precast UHPC girders. Liu et al. ${ }^{30}$ also performed pushoff tests of keyed interfaces for UHPC. Recent work has also studied UHPC to conventional concrete interface properties. ${ }^{31-36}$ Despite the aforementioned research, the underlying mechanisms of UHPC interface shear resistance have not yet been clearly defined, especially for monolithically cast UHPC.

\section{EXPERIMENTAL INVESTIGATION}

The experimental investigation included construction and testing of 11 interface shear specimens. The materials used to construct the specimens, the test matrix, and the test methods are described herein.

\section{Test matrix and specimen details}

The test matrix is shown in Table 1 and specimen details are shown in Fig. 1. With exception of the baseline specimens (BL-0.0), which did not include interface reinforcement, the nomenclature used to describe specimens included two terms. The first term, "N" or " $\mathrm{H}$," indicates the strength of reinforcing steel crossing the interface. The term "N" indicates normal-strength reinforcing steel classified as U.S. Grade 40 (Grade $280 \mathrm{MPa}$ ) or U.S. Grade 60 (Grade 420 $\mathrm{MPa})$, and the term " $\mathrm{H}$ " indicates high-strength reinforcing

Table 1-Test matrix

\begin{tabular}{c|c|c|c|c|c|c}
\hline Specimen ID & UHPC batch ID & $\begin{array}{c}\text { Interface reinforcement } \\
\text { bar quantity }{ }^{*} \text { and size }\end{array}$ & $\begin{array}{c}\text { Grade of interface steel, } \\
\text { ksi (MPa) }\end{array}$ & $\rho_{v}, \%$ & $\begin{array}{c}\text { Clamping stress } \\
\text { ksi (MPa) }\end{array}$ & $\begin{array}{c}\text { Compressive strength of UHPC on } \\
\text { day of test }{ }^{\ddagger}, \mathrm{ksi}(\mathrm{MPa})\end{array}$ \\
\hline BL-0.0 & 1 & na & $40(280)$ & 0.00 & 0.00 & $21.2(146)$ \\
\hline N-0.24 & 2 & 2-U.S. No. 3 (M10) & $40(280)$ & 0.73 & $0.29(2.0)$ & $23.2(160)$ \\
\hline N-0.73 & 2 & 6-U.S. No. 3 (M10) & $40(280)$ & 0.98 & $0.39(2.7)$ & $22.9(158)$ \\
\hline N-0.98 & 2 & 8-U.S. No. 3 (M10) & $60(420)$ & 1.38 & $0.83(5.7)$ & $22.4(154)$ \\
\hline N-1.38 & 3 & 4-U.S. No. 5 (M16) & $60(420)$ & 2.07 & $1.24(8.6)$ & $20.9(144)$ \\
\hline N-2.07 & 4 & 6-U.S. No. 5 (M16) & $60(420)$ & 2.76 & $1.66(11.4)$ & $22.9(158)$ \\
\hline N-2.76 & 5 & 8-U.S. No. 5 (M16) & $120(820)$ & 1.38 & $1.66(11.4)$ & $23.3(161)$ \\
\hline H-1.38 & 6 & 4-U.S. No. 5 (M16) & $120(820)$ & 2.07 & $2.48(17.1)$ & $22.5(155)$ \\
\hline H-2.07 & 7 & 6-U.S. No. 5 (M16) & $120(820)$ & 2.76 & $3.31(22.8)$ & $24.2(167)$ \\
\hline H-2.76 & 8 & 8-U.S. No. 5 (M16) & & $25.4(175)$ \\
\hline
\end{tabular}

*Total number of bars crossing interface.

'Based on specified yield, $f_{y}$, strength of steel and nominal interface area, $A_{c v}$.

${ }^{\ddagger}$ Average of three cylinders.

§Two replicate specimens tested; denoted "A" and "B."

Note: na is not applicable. 


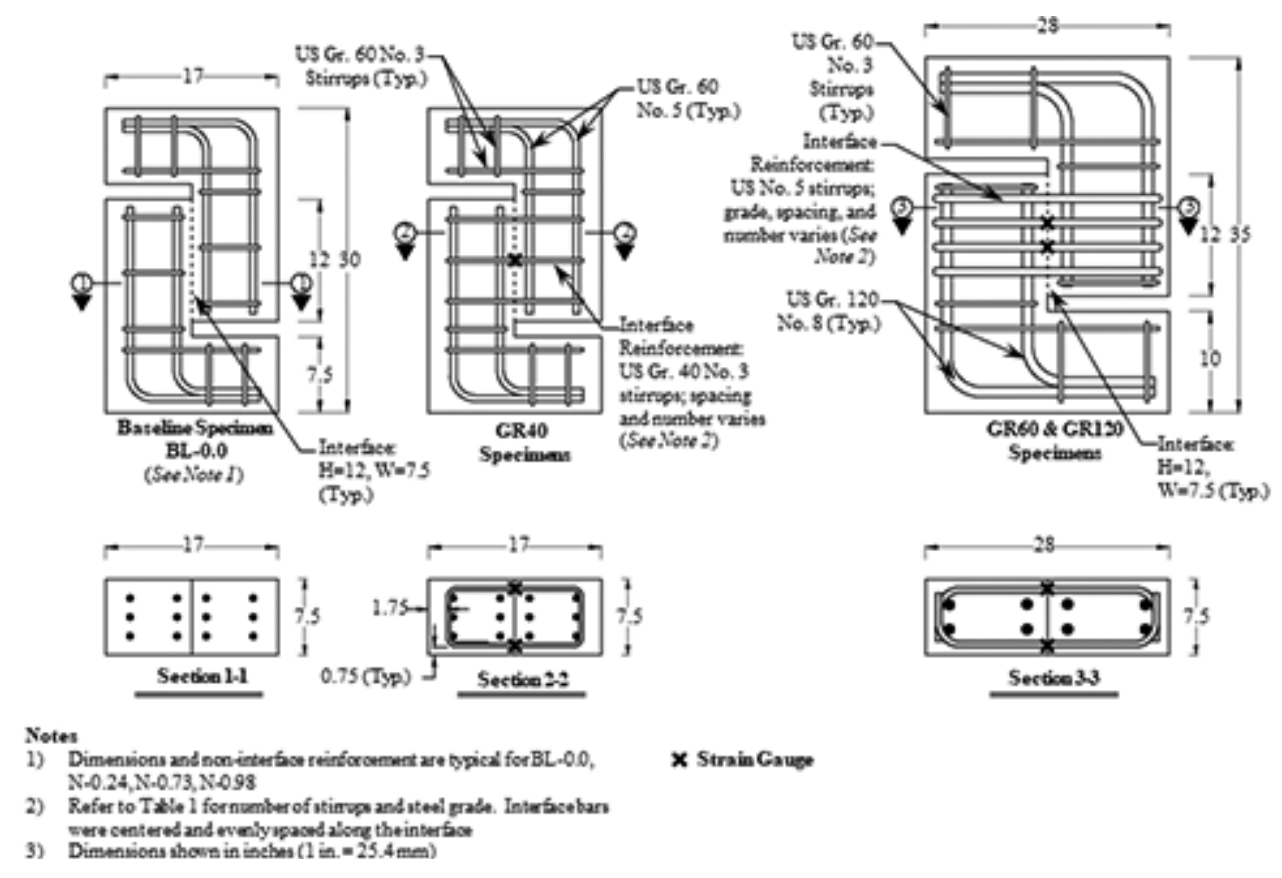

Fig. 1-Specimen details.

steel classified as U.S. Grade 120 (Grade $820 \mathrm{MPa}$ ). The second term, "\#.\#\#", indicates the reinforcement ratio (as a percentage) of reinforcing steel crossing the interface. Herein, the reinforcement ratio of steel, $\rho_{v}$, was taken as the ratio of the reinforcing steel area crossing the interface, $A_{s v}$, to the area of the interface, $A_{c v}$.

Typical s-shaped, single-shear, pushoff specimens were used to investigate the interface shear resistance. An s-shaped, single-shear, pushoff specimen is commonly used to investigate the interface shear behavior of conventional and high-strength concretes. ${ }^{15}$ Two specimen geometries were employed, depending on the level of interface conventional reinforcement present. The geometries allowed for adequate development length for the interface reinforcement. ${ }^{37}$ The nominal shear area at the monolithic interface was constant regardless of overall specimen geometry; $A_{c v}$ $=90$ in. $^{2}\left(580 \mathrm{~cm}^{2}\right)$. The baseline specimens and specimens with U.S. Grade 40 (Grade $280 \mathrm{MPa}$ ) interface reinforcement were of a smaller size, allowing multiple specimens to be cast from the same batch of UHPC.

\section{Specimen fabrication}

Specimens were fabricated at the FHWA Structural Testing Laboratory. Specimens were cast monolithically by pouring a continuous stream of fresh UHPC into the lower knee of the specimen and letting it freely flow across the interface region until the mold was full; photos and additional details are presented in Appendix II. The specimen casting method may have created preferential orientation of fibers perpendicular to the interface shear plane because fibers tend to align with the direction of flow as has been demonstrated in the literature. ${ }^{38,39}$ The authors chose this placement method for consistency across specimens.

\section{Details and properties of UHPC}

The UHPC-class material used in this study was a commercial product available in the U.S. market. The commercial product had five primary constituents that were supplied by the manufacturer: a preblended, prebagged powder mixture containing all of the solids (with the exception of fibers); a modified phosphonate plasticizer; a modified polycarboxylate high-range water-reducing admixture; a non-chloride accelerator; and steel microfiber reinforcement. The steel microfiber reinforcement had a manufacturer-reported tensile strength greater than $290 \mathrm{ksi}(2000 \mathrm{MPa})$. The fibers had a nominal length of 0.5 in. $(12.7 \mathrm{~mm})$ and a nominal diameter of 0.008 in. $(0.2 \mathrm{~mm})$. The solids included in the preblended, prebagged powder included fine sand, ground quartz, silica fume, and portland cement. The mixture had a water-cementitious materials ratio $(w / \mathrm{cm})$ less than 0.25 by mass. The UHPC mixture was dosed with $2 \%$ steel fibers by volume. The static flow of the UHPC was measured for each batch per ASTM C1856 $6^{40}$ and was consistently in the range of 8.5 to $10.0 \mathrm{in}$. (216 to $254 \mathrm{~mm}$ ). The compressive strength of the UHPC mixture was consistently above $21 \mathrm{ksi}(145 \mathrm{MPa})$ after 14 days of curing in a sealed mold at ambient laboratory conditions; the lab temperature was $72^{\circ} \mathrm{F}\left(22.2^{\circ} \mathrm{C}\right)$. Compression testing was executed according to ASTM C1856. ${ }^{40}$

The tensile mechanical properties of UHPC-class materials are distinctly different from those of conventional cementitious composite materials. Herein, the direct tension properties of UHPC are used to develop a predictive capacity model. As such, a detailed description of UHPC's direct tension response is provided in the following text. Figure 2(a) depicts two distinct tensile stress-strain responses for UHPC.

The tensile response of UHPC-class materials has three distinct phases. The elastic phase (phase 1 in Fig. 2(a)) is characterized by an initial linearly elastic response, defined by the modulus of elasticity, $E_{U H P C}$, until the apparent tension cracking strength, $f_{t, c r}$, is reached. The next phase (phase 2 in Fig. 2(a)) is described as either: 1) a stress-plateau range, where the post-first-crack stress remains 


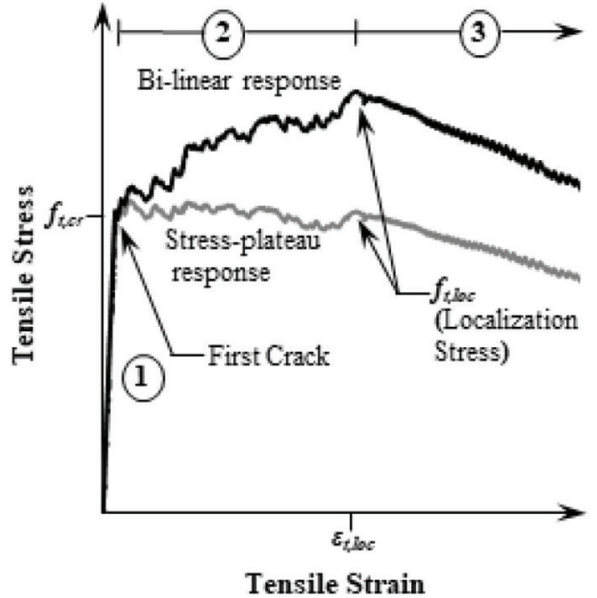

(a)

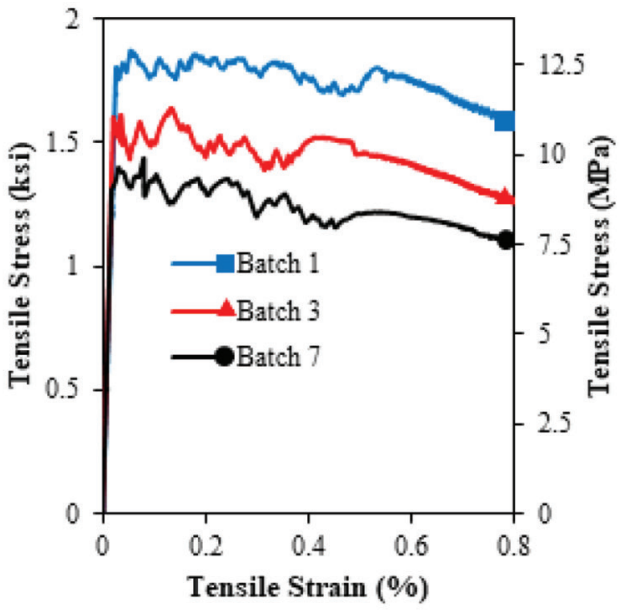

(b)

Fig. 2-(a) Typical tensile stress-strain behavior of UHPC; and (b) select tensile stress-strain responses from UHPC used within this study.

relatively constant; or 2) a bilinear response, where the post-cracking resistance gradually increases until the peak tensile resistance is reached. Phase 2 is characterized by multi-cracking behavior of UHPC. During multi-cracking, steel fibers bridge the cracks, which generally prevents the crack widening, and allows stress capacity to be maintained (for stress-plateau models) or increased (for bilinear models) as additional strain is applied. Phase 2 concludes once the localization strain $\left(\varepsilon_{t, l o c}\right)$ is reached. In the final phase (phase 3 in Fig. 2(a)), additional tensile deformation is localized into an individual crack, which continues to widen as the fibers that bridge the crack debond and pull out of the matrix. During phase 3, the stress will continuously decrease and the response is dependent on localized deformation, not global strain. ${ }^{41}$ The reader is referred to the literature for additional information on the tension response of UHPC., 1,2,42

Herein, tension testing of UHPC was executed based on the work by Graybeal and Baby ${ }^{42}$ using prisms, which were created during the casting of interface shear specimens. A minimum of four prisms were cast for each batch. Average tension properties were determined using the method described by El-Helou et al. ${ }^{1}$; the average tension properties used in the predictive capacity model are presented herein. Tension test specimens that exhibited crack localization outside of the intended extensometer gauge length were not included in the data analysis. As such, there were some cases where only two or three prisms were used in determining the average tensile material properties of UHPC. Figure 2(b) depicts a set of representative tensile stress-strain curves for the UHPC used for the study presented herein. A summary of the tensile material properties of UHPC are listed in Appendix II.

\section{Properties of steel reinforcement}

Three different grades of steel reinforcement were used in this study as interface reinforcement: 1) ASTM A615 ${ }^{43}$ U.S. Grade 40 No. 3 (Grade 280 MPa Ø10); 2) ASTM A615 ${ }^{43}$ U.S. Grade 60 No. 5 (Grade $420 \mathrm{MPa} \varnothing 16$ ); and 3) ASTM A1035 $5^{44}$ U.S. Grade 120 No. 5 (Grade $820 \mathrm{MPa}$ Ø16) bars. The average measured tensile properties of the steel reinforcement are listed in Appendix II, and representative measured stress-strain curves are shown in Appendix II. Additional steel reinforcement sizes and grades were used to reinforce other parts of the specimens away from the interface plane, and these are denoted in Fig. 1.

\section{Instrumentation and testing}

Specimens were instrumented using two different methods: 1) electrical resistance strain gauges on reinforcing bars; and 2) digital image correlation (DIC) on the surface of the test specimen. The strain gauge locations are denoted in Fig. 1. Specimen deformations were captured using a commercially available DIC system. The system consisted of cameras facing both sides of the interface, positioned to view the entire specimen from the spherical bearing above the specimen to the support plates below the specimen. Virtual displacement gauges, created in the DIC system, were used to capture interface slip, specimen rotation, surface strains in UHPC across the interface, and displacement of the hydraulic loading ram. The locations of the virtual gauges are shown in Fig. 3(a). The horizontal virtual gauges (crossing the interface) had a gauge length of 6 in. $(152.4 \mathrm{~mm})$. The vertical virtual gauges measuring the slip had a gauge length of 4 in. $(101.6 \mathrm{~mm})$ and the vertical virtual gauges measuring the displacement near the bottom of the specimen had a gauge length of 6 in. (152.4 mm).

The test setup used in this investigation is shown in Fig. 3(b). Specimens were tested upright in a load frame that employed a servo-hydraulic ram capable of applying $600 \mathrm{kip}$ $(2670 \mathrm{kN})$ of force. Specimens were carefully installed into the load frame, such that the interface shear plane was vertically aligned with the applied load path. Each specimen was leveled and plumbed prior to being grouted in place on steel bearing pads using high-strength grout. Load was applied at an initial rate of $0.05 \mathrm{in} . / \mathrm{min}(1.27 \mathrm{~mm} / \mathrm{min})$ prior to rupture of the interface, and $0.1 \mathrm{in} . / \mathrm{min}(2.54 \mathrm{~mm} / \mathrm{min})$ thereafter for specimens with post-rupture, load-carrying capacity. The initial loading rate was employed to closely match the testing protocols described by Haber et al. ${ }^{6}$ 


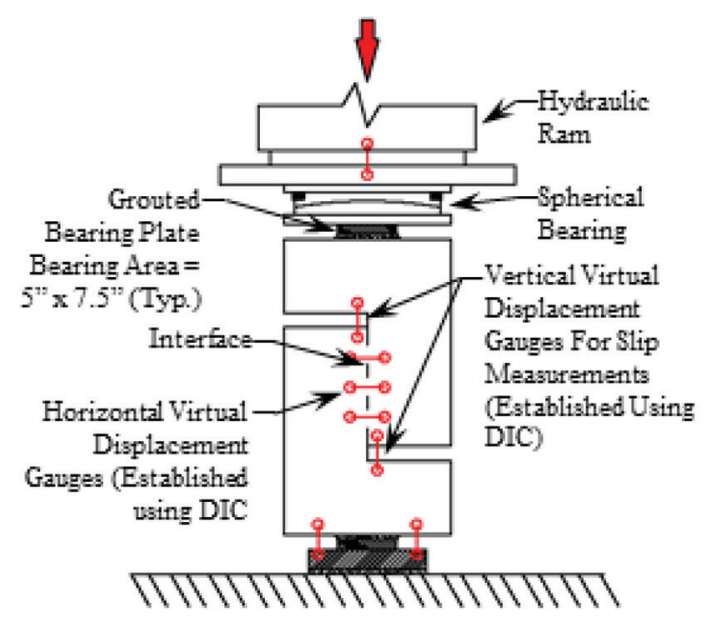

(a) Instrumentation schematic

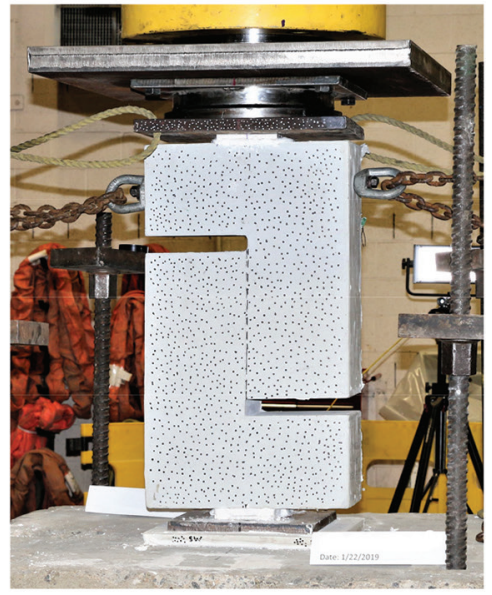

(b) Test setup photo

Fig. 3-Instrumentation and test setup.

Table 2-Summary of test results

\begin{tabular}{|c|c|c|c|c|c|c|c|}
\hline Specimen ID & $\begin{array}{c}\text { Shear stress at } 1 \text { st crack } \\
\text { ksi }(\mathrm{MPa})\end{array}$ & $\begin{array}{l}\text { Reinforcement clamping stress at } \\
\text { peak load, } \rho_{v} f_{s, p e a k}{ }^{\dagger}, \operatorname{ksi}(\mathrm{MPa})\end{array}$ & $\begin{array}{c}f_{t, l o c^{*}} \\
\mathrm{ksi}(\mathrm{MPa})\end{array}$ & \begin{tabular}{|c|} 
Shear stress at peak \\
load, ksi $(\mathrm{MPa})$
\end{tabular} & $\begin{array}{l}\text { Slip at peak load, } \\
\text { in. }(\mathrm{mm})\end{array}$ & $\varepsilon_{s}^{\S}, \%$ & $\varepsilon_{y, m}<\varepsilon_{s}$ \\
\hline BL-0.0A & Not avail. & $0.00(0.00)$ & $1.66(11.4)$ & $3.69(25.4)$ & $0.0402(1.02)$ & na & na \\
\hline $\mathrm{N}-0.24$ & $1.84(12.7)$ & $0.13(0.9)$ & $1.75(12.1)$ & $3.79(26.1)$ & $0.0502(1.28)$ & 0.333 & yes \\
\hline $\mathrm{N}-0.73$ & $1.24(8.5)$ & $0.39(2.7)$ & $1.75(12.1)$ & $3.63(25.0)$ & $0.0422(1.07)$ & 0.307 & yes \\
\hline $\mathrm{N}-1.38$ & $1.21(8.4)$ & $1.07(7.4)$ & $1.43(9.6)$ & $4.46(30.8)$ & $0.0605(1.54)$ & 0.318 & yes \\
\hline $\mathrm{N}-2.07$ & $1.26(8.7)$ & $1.64(11.3)$ & $1.44(9.9)$ & $5.03(34.7)$ & $0.0745(1.89)$ & 0.291 & yes \\
\hline $\mathrm{N}-2.76$ & $1.49(10.2)$ & $2.14(14.8)$ & $1.53(10.5)$ & $5.24(36.2)$ & $0.0741(1.88)$ & 0.276 & no \\
\hline H-1.38 & $1.59(11.0)$ & $1.28(8.8)$ & $1.17(8.1)$ & $5.04(34.8)$ & $0.0650(1.65)$ & 0.316 & no \\
\hline
\end{tabular}

*Data for shear stress and strain at first crack was estimated using change in slope of reinforcement strain data; recognize subjective selection of data point, and limitations inherent in measuring very small strains.

'Based on stress in reinforcing bar at time of peak load, $f_{s, p e a k}$ and measure interface area, $A_{c v, m}$.

Obtained from direct tension tests of companion specimens cast from same batch.

${ }^{\S}$ Strain in interface reinforcement at time of peak load based on average strain measured by strain gauges.

Notes: Not avail. $=$ not available (no strain gauge data was available); na = not applicable.

\section{EXPERIMENTAL RESULTS}

This section presents experimental results from this research. A summary of the key test results is listed in Table 2.

\section{Force-deformation behavior}

This research facilitated development of a general understanding of the interface shear behavior of UHPC and provided some general knowledge related to force-deformation behavior and failure modes. A representative set of interface shear stress versus slip curves is shown in Fig. 4. Shear stress is defined as the applied force divided by the area of the interface, and slip is defined as the relative displacement between the two planes parallel to and on either side of the interface plane. Slip was determined by averaging the four (two on each face) vertical virtual displacement gauges spanning the gap between the two L-shaped halves of the specimen, as seen in Fig. 3(a).

Figure 4(a) depicts the shear stress-slip behavior of specimens prior to and just after peak load is reached. All specimens exhibited approximately the same initial stiffness. All specimens also exhibited softening prior to achieving peak load. The softening was especially prevalent in specimens that incorporated high-strength steel (H-X.XX specimens). All specimens exhibited a significant drop in load-carrying capacity after the peak load was achieved. The drop in load is attributed to crack localization of the UHPC. After localization of UHPC, the load is assumed to be carried by the interface reinforcement alone as the localized UHPC has reduced to no load-carrying capacity.

Figure 4(b) shows the stress-slip curves in their entirety; specimen BL-0.0A is not shown in Fig. 4(b) because it did not have post-peak load-carrying capacity. The drop in 


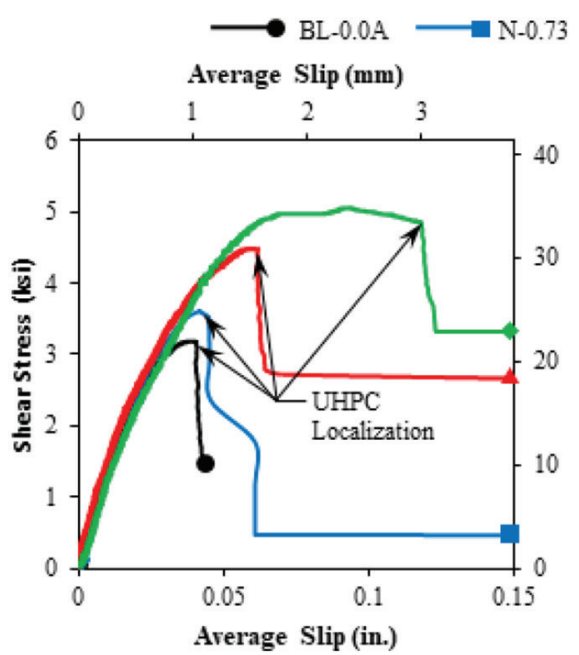

(a)

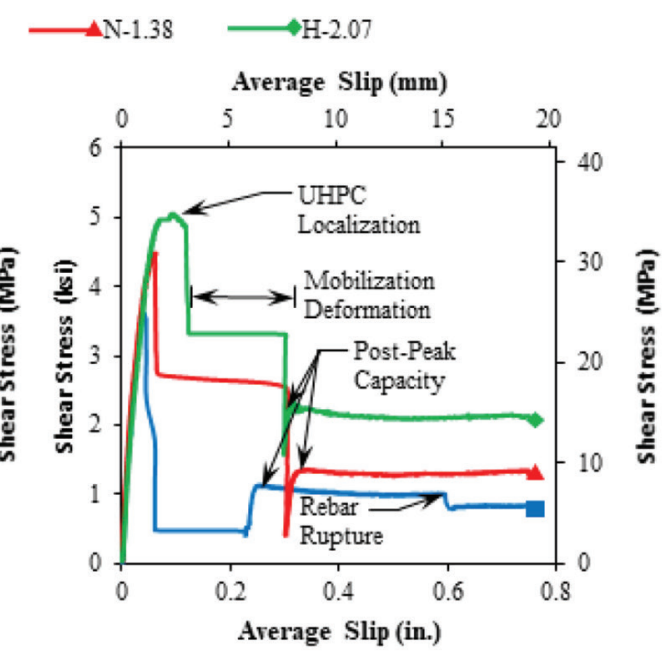

(b)

Fig. 4-Shear stress versus slip of select interface shear specimens with: (a) expanded view of early portion of response; and (b) full response.

load-carrying capacity coincided with a sudden increase in slip of the upper L-shaped portion of each specimen, which is herein defined as the "mobilization deformation" and is identified in Fig. 4(b). The mobilization deformation was caused by loss of UHPC's stress capacity due to localization. Mobilization of the upper L-shaped portion of each specimen was arrested by the interface reinforcement. As observed in Fig. 4(b), after the mobilization deformation occurs, specimens could retain some post-peak capacity at a relatively constant level throughout the remainder of the loading protocol; loading was stopped when the slip was approximately $1 \mathrm{in}$. $(25.4 \mathrm{~mm})$, due to geometric constraints of the specimens. Post-peak shear stress capacity is discussed in Appendix III.

\section{Failure modes}

A representative image of a specimen after testing can be observed in Fig. 5; additional photos are provided in Appendix III. Here, the solid black horizontal lines marked on the specimen represent the location of the interface reinforcement. Specimens without interface reinforcement exhibited UHPC localization and fracture along the vertical plane of the interface, which caused these specimens to separate into two L-shaped halves. For specimens with interface reinforcement, once crack localization and mobilization deformation occurred, UHPC fibers had been effectively pulled out and disengaged from the load-transfer mechanism. As the interface reinforcement ratio increased, there were some diagonal cracks that formed in the interface shear region. Localization and fracture of UHPC occurred along the intended vertical interface plane for all specimens. For specimens with interface reinforcement, the localized crack pulls apart far enough such that the fibers no longer bridge the opening, but the interface is still held together by the steel reinforcing bars. After the crack localized, a significant drop in load was observed. The specimen was considered to have failed at this point.

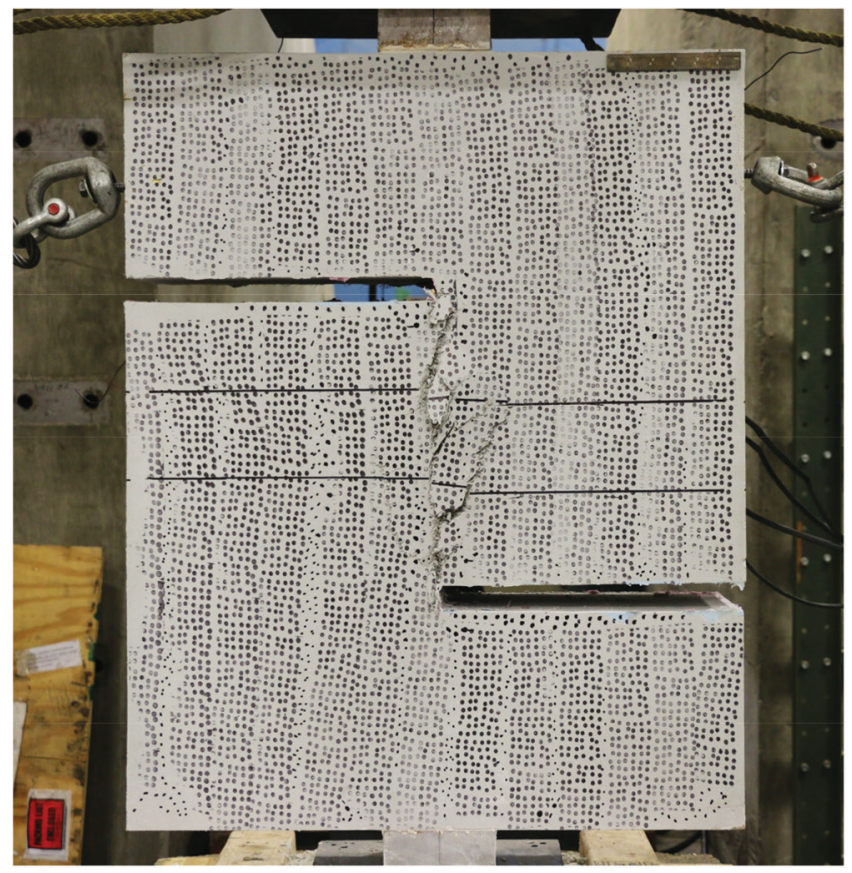

Fig. 5-Representative image of specimen after failure.

\section{Shear stress capacity trends}

The shear stress capacity of the tested specimens is shown in Fig. 6 as a function of the clamping pressure; this representation aligns with the traditional notion of the shear friction theory and does not account for the tensile properties of UHPC. Here, the clamping pressure is defined as the interface reinforcement ratio, $\rho_{b}$ multiplied by the stress in the interface reinforcement at the time of peak load, $f_{s, p e a k}$. If the reinforcement yielded prior to the peak load, then $f_{\text {s,peak }}$ was taken as $f_{\text {y,measured. }}$. If the reinforcement did not yield, then $f_{s, p e a k}$ was determined using Hooke's Law with the measured strain in the reinforcement, which was determined with strain gauge data.

Specimens without steel reinforcing bars crossing the interface exhibited a shear stress capacity between 3.2 and 


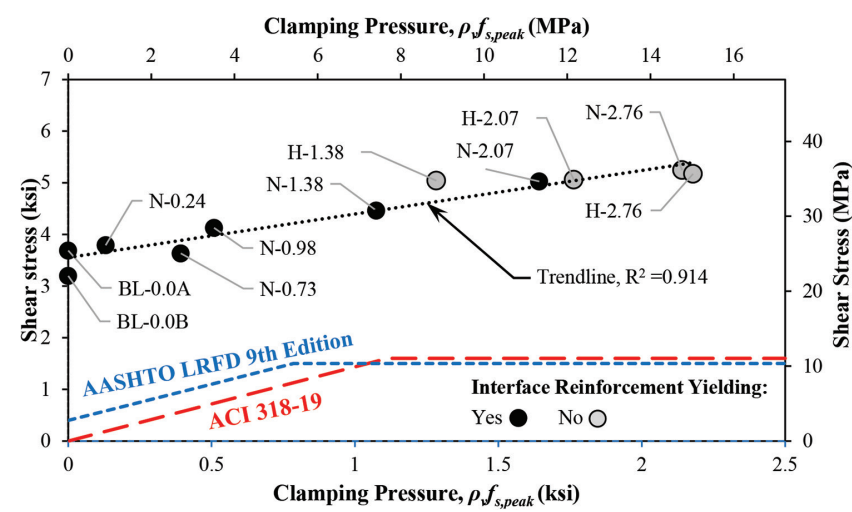

Fig. 6-Shear stress versus clamping pressure of tested specimens.

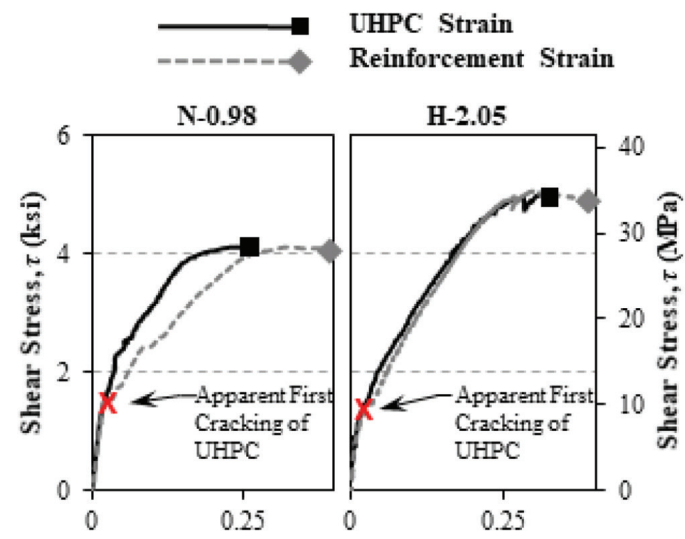

Strain Normal to Interface, $\varepsilon_{n}(\%)$

Fig. 7-Shear stress versus strain normal to interface of UHPC and interface reinforcement of select specimens.

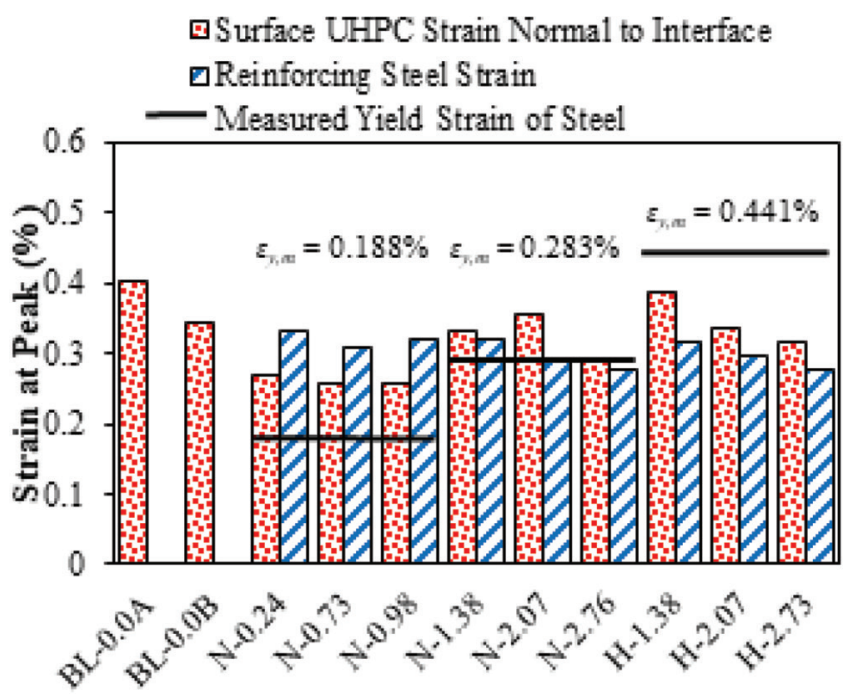

Fig. 8-Reinforcing steel strains and UHPC strain normal to interface at peak load.

$3.69 \mathrm{ksi}(22.0$ and 25.4 MPa); previous research on UHPC interface shear demonstrated capacities ranging from 2.55 to $2.92 \mathrm{ksi}$ (17.6 to $20.1 \mathrm{MPa}$ ), depending on the UHPC fiber volume fraction..$^{26,27,45}$ For specimens with interface shear reinforcement, it is evident that the interface shear capacity is proportional to the amount of interface reinforcement provided (clamping pressure).
Figure 6 also illustrates the ACI and AASHTO nominal capacities for normalweight, monolithically cast concrete. Both equations use a friction factor of 1.4; however, AASHTO allows for an initial intercept (referred to as cohesion within the code) of $0.40 \mathrm{ksi}(2.76 \mathrm{MPa})$. The equations were applied in Fig. 6, assuming compressive strength greater than $14 \mathrm{ksi}(96.5 \mathrm{MPa})$. The existing ACI and AASHTO code provisions do not capture the behavior of UHPC-class materials, and provide an overly conservative estimate of capacity.

The trendline shown in Fig. 6 has a smaller slope than the ACI and AASHTO capacities. The trendline slopes correspond to the friction coefficient, $\mu$, if applying the traditional model of shear friction of monolithically cast concrete. UHPC has a significantly higher tensile strain capacity than conventional concrete and, as such, one may theorize that the wider separation at the interface may result in less friction. The wider separation may be the reason for the lower friction coefficient for UHPC.

\section{Measured strains}

Horizontal strains on the surface of UHPC were measured using three virtual displacement gauges positioned along the interface (shown in Fig. 3(a)). The horizontal strains were normal to and measured across the interface, and are herein defined as the normal strain, $\varepsilon_{n}$, across the interface. Strain was also measured from the internal steel reinforcing bars using strain gauges. Figure 7 compares UHPC surface strain normal to the interface $\left(\varepsilon_{n}\right)$ with the average strain measured from interface reinforcement for a representative set of specimens. The curves were also truncated at the peak shear stress. The key observation here is that the surface strain in UHPC and the strains in the reinforcement remain relatively similar throughout the loading history. That is, there is apparent compatibility between the UHPC and interface reinforcement. Additionally, both strain types exhibit softening after the initially linear ascending branch of the curve. The softening is attributed to apparent first cracking of the monolithic UHPC interface, which was corroborated by observations made during physical testing. The initial change in slope was used as a rough indicator of the apparent first cracking stress of the interface. In some cases, the change in slope was not abundantly clear, and some judgment was required to identify apparent first cracking. Therefore, the data obtained from the curves may only be considered an estimation of the first crack stress. Apparent first cracking was commonly found to occur at a shear stress between 1.2 and $1.9 \mathrm{ksi}(8.3$ and $13.1 \mathrm{MPa})$. Ideally, the UHPC strain data would provide the best indication of apparent first cracking. However, the resolution of the digital image correlation (DIC) system was set up to capture the localization strains and, thus, the sensitivity of the equipment was not adequate at the significantly lower strain at apparent first cracking. Future studies may require additional instrumentation to obtain more precise first-crack data.

The strains in the reinforcement and strains in the UHPC normal to the interface at peak load are presented in Fig. 8. It can be observed that the strains in the UHPC at peak load remained relatively constant among all specimens. 
Furthermore, the strains in the reinforcing steel also remained relatively constant. Black lines drawn on Fig. 8 represent the measured yield strains of interface reinforcement for comparison. For specimens with U.S. Grade 40 (Grade 280 $\mathrm{MPa}$ ) reinforcement, the yield strain is well below the strains at peak load, indicating that the interface reinforcement has yielded. The strains at peak load for specimens made with U.S. Grade 60 (Grade $420 \mathrm{MPa}$ ) reinforcement compared to the yield strain are relatively similar. Finally, specimens made with U.S. Grade 120 (Grade $820 \mathrm{MPa}$ ) reinforcement had strains at peak load well below the yield strain of the reinforcement. Typical interface shear design provisions rely on the yield properties of the reinforcing steel to calculate the clamping pressure portion of the capacity equation. However, the data demonstrate that with UHPC, the yield properties may not be appropriate to use within the equation, as some specimens reached their peak load prior to reinforcement yielding. Furthermore, the constant UHPC strain at peak load, which is consistent with the material's typical tension localization properties, provides an indication that a limiting factor in the interface capacity is the tensile localization strain of the UHPC.

It is acknowledged that the surface UHPC strain normal to the interface, as presented herein, may be slightly different from actual principle tensile UHPC strain at the interface. The gauge length of the UHPC strain measurement was 6 in. $(152 \mathrm{~mm})$; in the interface shear tests, the strain would not be evenly distributed across the interface like it would be during a typical direct tension test capturing the uniaxial tensile mechanical response. Furthermore, the slip or displacement parallel to the interface may also provide slight differences in the measured strain and actual strain; despite this, the UHPC strain presented herein provides a semiquantitative indication of the structural response of the interface.

\section{Discussion}

The findings demonstrate that the localization strain of UHPC is a limiting factor in the interface shear capacity of UHPC and, as such, needs to be considered for development of nominal (design) capacity models. Using the shear friction theory, conventional concretes cannot achieve additional capacity once yielding of steel occurs because, in theory, the interface is able to mobilize due to post-yielding deformation of steel. In contrast, the tensile strain capacity of UHPC allows it to make a significant contribution to the capacity of the interface. When the yield strain of the reinforcement is less than the localization strain of the UHPC, the reinforcement is the limiting factor. The reinforcement is the limiting factor because as the reinforcement yields and reaches the inelastic plateau regions of a stress-strain curve, any additional stress must be resisted only by the UHPC, which would then quickly localize. Conversely, if the yield strain of the reinforcement is greater than the localization strain of UHPC, the UHPC is the limiting factor. When UHPC is the limiting factor, the UHPC could localize and begin offering reduced resistance prior to the steel reinforcing bars offering the full resistance commensurate with their yield strength. The observations regarding limiting factors will be incorporated into the proposed capacity model developed herein.

\section{STRUCTURAL RESPONSE OF UHPC IN INTERFACE SHEAR}

This section presents the generalized structural response and governing resistance mechanisms of monolithic UHPC subjected to interface shear. The primary mechanism that governs the response of UHPC subjected to interface shear is effectively the same as that which governs conventional concrete: the theory of shear friction. That is, that the interface shear capacity is primarily dependent on both the clamping pressure normal to the interface and the friction coefficient inherent to the material being sheared. The difference, in the case of UHPC, is that clamping pressure is provided by both the interface-crossing reinforcing bars and the tensile resistance of UHPC. Furthermore, the inherent difference in material properties (that is, the lack of coarse aggregates and the high volume of fiber reinforcement) lead to a unique structural response in the case of UHPC.

The generalized structural response of UHPC subjected to interface shear is presented in Fig. 9. Figure 9(a) illustrates the test specimen, the applied load, and the region of interest for the following discussion. Figure 9(b) illustrates a typical shear stress versus slip curve for UHPC subjected to interface shear. Key points of interest along the curve have been annotated, which correspond to the actions shown in Fig. 9(c) through (f). A point-by-point description of the structural response is presented herein:

- $\quad$ Point 0 to Point 1: Within point 0 to point $1, \mathrm{UHPC}$ is linear-elastic and deformation (slip) is restrained by the monolithic UHPC, as shown in Fig. 9(c).

- $\quad$ Point 1: Point 1 corresponds to apparent first cracking of the UHPC along the interface as shown in Fig. 9(d). It is expected that at point 1 , the crack is very fine and virtually no mobilization has occurred.

- $\quad$ Point 1 to Point 2: After apparent first cracking of UHPC, the interface reinforcing steel begins to become more engaged in the resistance to the applied shear force. The engagement is corroborated by the data presented in Fig. 7, which demonstrates that after the apparent cracking point, the strain in the reinforcing steel begins to increase more rapidly. The reasoning for the change is as follows: the crack plane formed in UHPC will naturally have some roughness. As the two UHPC segments on either side of the crack move relative to each other, there will be a tendency for separation normal to the interface. The movement is analogous to that which occurs due to coarse aggregates in conventional concrete. As a result, strain normal to the interface will increase, which will increase the demand on the reinforcing steel. Point 1 to point 2 is also characterized by increasing strains in the UHPC from the crack widening (Fig. 9(e)). Due to the fiber reinforcement, the UHPC can provide tensile resistance and contribute to the clamping pressure along with the steel reinforcement.

- $\quad$ Point 2: At point 2, the primary interface crack begins the process of localization and, as a result, the structural system begins to soften.

- $\quad$ Point 2 to Point 3: Within point 2 to point 3, UHPC approaches the fiber-bridging strain limit. The 


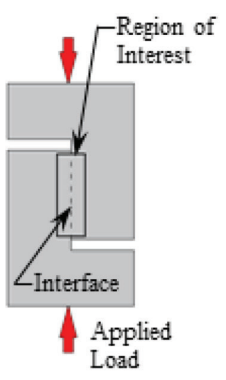

(a)

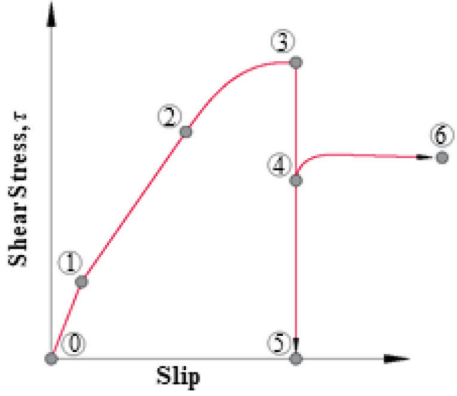

(b)

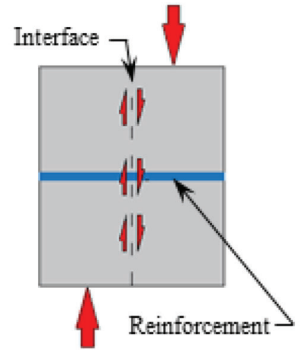

(c)

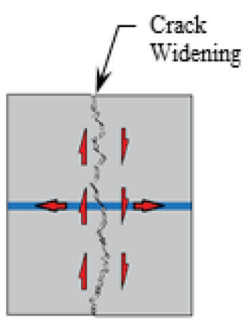

(e)

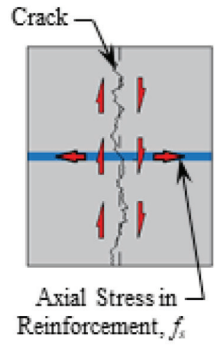

(d)

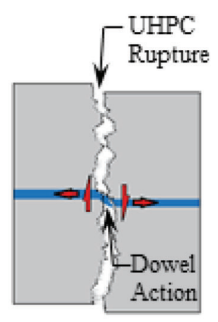

(f)

Fig. 9-Generalized structural response of UHPC exposed to interface shear with: (a) interface specimen; (b) typical stressversus-slip curve; (c) interface behavior within UHPC elastic range; (d) interface behavior just after UHPC first crack; (e) interface behavior prior to UHPC localization; and (f) interface behavior after UHPC localization.

fiber-bridging strain limit will also coincide with the occurrence or nonoccurrence of steel reinforcement yielding. If the steel reinforcement yields, any additional stress must be accommodated by the UHPC. Because the UHPC cannot accommodate any additional stress (if a stress plateau UHPC tensile response is considered) or can only accommodate minimal additional stress (if a bilinear UHPC tensile response is considered), the strain in the UHPC rapidly approaches the fiber bridging limit. Alternatively, the steel reinforcement may not have yielded, depending on the yield strain limit, but the UHPC would still have localized (at Point 2). The UHPC would begin supplying reduced resistance and would eventually reach the fiber bridging strain limit, while the strain and stress in the steel reinforcement was continuing to increase toward yield. The information used to define the behavior between points 2 and 3 is based on the measured strains presented in Fig. 7 and Fig. 8.

- Point 3: Once the fiber bridging strain limit is reached, fibers will have pulled out from the cementitious matrix. At point 3, the UHPC has undergone complete rupture. After point 3, the behavior is governed by the quantity of interface reinforcement, if any.

- Point 3 to Point 5: After rupture of UHPC, the system loses all load bearing capacity if interface reinforcement is not present.

- Point 3 to Point 4: If reinforcement is present within the system, residual (post-peak) resistance can be realized, which is provided by the reinforcement. The system will undergo a decrease in load-carrying capacity, but will be restrained by the reinforcement provided (Fig. 9(f)). The system's behavior was also observed within this research, as demonstrated in Fig. 4.

- Point 4: Point 4 is the immediate post-UHPC-rupture residual capacity of the system.
- $\quad$ Point 4 to Point 6: Point 4 to point 6 is characterized by residual resistance provided only by the steel reinforcement. The post-peak stress observed within point 4 to point 6 closely resembles the typical clamping pressure calculated from the product of the reinforcement ratio and reinforcement yield stress, as demonstrated in Appendix III. The post-peak shear stress remains relatively constant for the remainder of applied deformation until the reinforcement reaches tensile rupture.

For design purposes, the most critical portion of the structural response is what occurs between point 0 and point 3 , where point 3 would be considered the design capacity (without any applied resistance factors). To demonstrate the structural response, the shear stress versus the total clamping pressure is shown in Fig. 10, with the formulation for clamping pressure having been modified to incorporate the concepts just discussed. Two sets of data points are shown: 1) data corresponding to the apparent first cracking of the UHPC at the interface (point 1 from Fig. 9(b)); and 2) the data corresponding to peak load resisted by the specimen (point 3 from Fig. 9(b)). Here, the total clamping pressure at peak load is defined by the tensile contributions from both reinforcing steel and UHPC, with $f_{s, p e a k}$ being the stress in steel at peak load. If the reinforcement yielded prior to peak load, $f_{\text {s,peak }}$ was taken as the measured yield stress from tensile testing (shown in Table 2). If the interface reinforcement did not yield, $f_{s, p e a k}$ was determined based on the measured strain at the time of peak load. UHPC's contribution to the clamping pressure comes from its tensile capacity at the time of localization, $f_{t, l o c}$. Like reinforcing steel, $f_{t, l o c}$ can be determined via tension testing. The $f_{t, l o c}$ values used herein are those listed in Table 2. A best-fit line is shown for the data points corresponding to peak load responses. The slope of the best-fit line of the data is approximately equal to 1.0 , and would be considered the friction coefficient $(\mu)$ in typical interface shear design provisions. The intercept coefficient, 


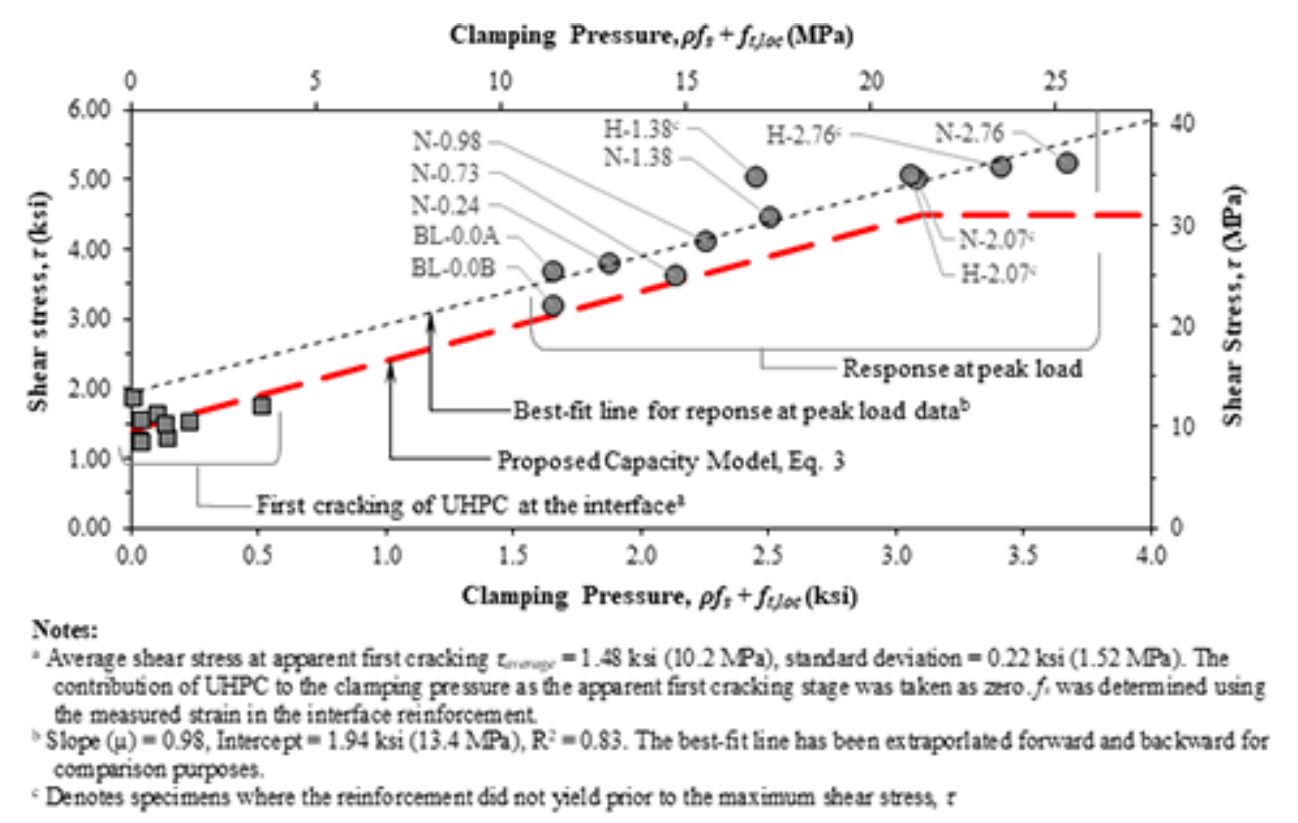

Fig. 10-Shear stress versus total clamping pressure of tested UHPC specimens.

which is $1.91 \mathrm{ksi}(13.2 \mathrm{MPa})$, is dependent on the elastic state response of the UHPC when there is no clamping force.

In Fig. 10, the clamping pressure for the first crack data points only includes the component from interface reinforcement. That is, no clamping force is contributed by the UHPC at apparent first cracking because the UHPC itself is resisting the shearing forces through the uncracked cementitious matrix. For the set of data, the stress in steel was determined using the strain in the bars at the time of apparent first cracking. The average shear stress of the data points across all specimens is $1.48 \mathrm{ksi}(10.2 \mathrm{MPa})$.

\section{PROPOSED CAPACITY MODEL}

The proposed capacity model is based on the observed structural response of interface shear test specimens. This section describes the assumptions for the model and the proposed capacity equations, and provides verification for the proposed model.

\section{Assumptions}

The following assumptions relate to the proposed capacity model:

- Steel reinforcement across the interface has adequate development length.

- Tensile strength of the UHPC to be considered within the capacity model must be obtained using a uniaxial tension test method, such as that developed by Graybeal and Baby. ${ }^{41}$ Furthermore, the fiber orientation of the specimens used for direct tension in relation to the loading direction must be consistent with the fiber orientation at the shear interface in relation to a plane perpendicular to that interface.

- Contributions from dowel action of interface reinforcement or steel fibers are neglected.

- UHPC is unable to provide any interface shear resistance after localization.
Table 3-Variables and values associated with proposed capacity model in Eq. (3)

\begin{tabular}{c|c|c}
\hline Variable & Symbol & Value \\
\hline $\begin{array}{c}\text { Friction factor for } \\
\text { monolithically cast UHPC }\end{array}$ & $\mu$ & 1.0 \\
\hline Stress in steel & $f_{s}$ & $\min \left[E s \cdot \varepsilon_{t, l o c}, f_{y}\right] \mathrm{ksi}(\mathrm{MPa})$ \\
\hline $\begin{array}{c}\text { Tensile strength of UHPC at } \\
\text { localization }\end{array}$ & $f_{t, l o c}$ & $\begin{array}{c}\text { Determined by direct tension } \\
\text { testing, but no greater than } \\
1.75 \mathrm{ksi}(12.1 \mathrm{MPa})\end{array}$ \\
\hline $\begin{array}{c}\text { y-intercept for capacity model } \\
\text { of monolithically cast UHPC }\end{array}$ & $c$ & $1.4 \mathrm{ksi}(9.8 \mathrm{MPa})$ \\
\hline $\begin{array}{c}\text { Material reduction factor } \\
\text { Limiting shear stress capacity } \\
\text { for monolithically cast UHPC }\end{array}$ & $\gamma$ & $\begin{array}{c}0.85(\mathrm{recommended} \text { based } \\
\left.\text { on work of El-Helou et al. }{ }^{1}\right)\end{array}$ \\
\hline
\end{tabular}

\section{Capacity equation}

The interface shear capacity may be calculated using the expression proposed in Eq. (3). Table 3 provides a concise summary of the associated variables and values used in Eq. (3). Equation (3) takes the general form of many common interface shear capacity equations. ${ }^{10,21}$ That is, nominal interface shear capacity, $V_{n}$, includes a component due to friction (the first term) and a component due to the inherent resistance of the cementitious material, sometimes referred to as cohesion (the second term). In conventional concrete, the friction term only includes clamping pressure from the interface reinforcement. Herein, the friction term for UHPC is also both a component due to the resistance of interface reinforcement and a component due to the tensile resistance of UHPC, which was discussed and demonstrated previously in this paper. The component due to the tensile resistance is taken as the tensile strength of UHPC at localization, $f_{t, l o c}$, which may be multiplied by a reduction factor, $\gamma$, to account for variability in material properties. Inclusion of the tensile strength term requires the designer to be cognizant of whether the localization strain of UHPC, $\varepsilon_{t, l o c}$, is 
greater than or less than the yield strain of the interface reinforcement, $\varepsilon_{y}$, as it controls what is selected for the clamping pressure component due to stress in steel reinforcement, $f_{s}$.

If $\varepsilon_{t, l o c}$ is more than $\varepsilon_{y}$, then the steel is assumed to yield prior to the ultimate capacity being reached and, as such, the component of clamping pressure due to steel, $f_{s}$, would be equal to $f_{y}$. Conversely, if $\varepsilon_{t, l o c}$ is less than $\varepsilon_{y}$, then the steel is assumed to not yield prior to the ultimate capacity being reached, and as such, its component of clamping pressure, $f_{s}$, would be governed by $\varepsilon_{t, l o c}$. Recalling that compatibility exists between UHPC and steel (refer to Fig. 7), $f_{s}$ would be calculated using Hooke's law, $f_{s}=E_{s} \cdot \varepsilon_{t, l o c}$. The usable clamping pressure due to steel is succinctly described in Table 3 using a minimum function.

The y-intercept for the capacity model (the coefficient $c$ ), which is commonly considered the cohesion factor, is taken as $1.4 \mathrm{ksi}(9.8 \mathrm{MPa})$ and is based on apparent first cracking strength of UHPC when subjected to interface shearing (refer to Fig. 10). The value of the cohesion factor was selected to add some inherent conservatism to the model. Refer to Fig. 10, which shows that the best-fit line for the response at peak load would place the intercept at approximately $c=2.0 \mathrm{ksi}(13.8 \mathrm{MPa})$. It is also important to note that traditionally, the cohesion factor for conventional concrete has been empirically derived and is based on the conditions of the interface at the time of construction (that is, monolithic or cold-jointed, and if cold-joint, whether that joint is rough or smooth). The value of $c$ in the AASHTO LRFD Bridge Design Specifications ${ }^{21}$ Article 5.7.4.4 varies from $0.0 \mathrm{ksi}(0.0 \mathrm{MPa})$ for brackets, corbels, and ledges, to $0.4 \mathrm{ksi}(2.8 \mathrm{MPa})$ for a monolithic interface composed of conventional, normalweight concrete. Herein, the value of $c$ $=1.4 \mathrm{ksi}(9.8 \mathrm{MPa})$ only holds for monolithically cast UHPC interfaces where the UHPC is mature in age and contains a minimum of $2.0 \%$ fiber reinforcement by volume; additional research will be required to fully capture a range of values for $c$.

$$
V_{n}=\left[\mu\left(A_{s v} f_{s}+A_{c v} \gamma f_{t, l o c}\right)+A_{c v} c\right]<K \cdot A_{c v}
$$

\section{Imposed limits}

It should be clear that there are some limits that have been imposed on the proposed model. The limits are required, given that there is still limited research on the subject of interface shear of monolithic UHPC. First, it can be noted in Eq. (3) that there is an upper bound of $4.5 \mathrm{ksi}$ (31 MPa) imposed on the shear stress capacity, which is denoted by the variable $K$. The upper bound is effectively placing an implicit limit on the effectiveness of the reinforcement provided across the interface. The limit is clearly shown in Fig. 10 by means of the red dashed line, which denotes the proposed capacity model. The second imposed limit is placed on the tensile resistance provided by the UHPC at localization. The second limit component, $f_{t, l o c}$, should be limited to $1.75 \mathrm{ksi}(12.1 \mathrm{MPa})$ until further research can be conducted to explore the relationship between interface shear capacity and the tensile properties of UHPC.

\section{Additional guidance}

The following items are points of additional guidance that should be considered by the designer:

- Determination of tensile properties of UHPC: The use of Eq. (3) relies heavily on an accurate determination of the tensile properties of the UHPC being used in design. The engineer should use their best judgment when interpreting the tensile material properties of UHPC, especially the localization strain value. A more conservative UHPC localization strain value will result in a more conservative design capacity for cases when $\varepsilon_{t, l o c}<\varepsilon_{y}$. However, when $\varepsilon_{t, l o c}>\varepsilon_{y}$, the localization strain is not directly included in the capacity equation.

- Fiber orientation in UHPC: The designer should consider the orientation of the interface and assure that the UHPC material properties used for design purposes are obtained from similar materials with similar fiber orientation.

- Presence of permanent compressive forces: ACI and AASHTO provisions provide guidance for permanent compressive forces across a shear plane; this force is commonly denoted by $P_{c}$. It may be reasonable to assume that the ACI and AASHTO guidance may also be applicable to UHPC.

- Orientation of steel reinforcing bars: ACI and AASHTO provisions provide guidance for cases where the interface reinforcing steel is not normal to the interface plane. It is reasonable that the same guidance may be relevant to UHPC; however, some caution should be applied as the guidance has yet to be explored for UHPC-class materials.

- $\quad$ Strength reduction factors: Lastly, the number of tests performed within this study was limited; therefore, additional research will likely be required to determine appropriate strength reduction factors $(\phi)$ to be used for design purposes.

\section{Verification}

To verify the proposed capacity model, the interface shear stress capacity obtained using Eq. (3) and the values listed in Table 3 was compared to the experimental data from this research and data from Crane, ${ }^{25}$ whose specimen geometry and testing methods were similar. To determine $\tau_{\text {calculated, }}$, the nominal properties of the steel reinforcement were used: $f_{y}=40 \mathrm{ksi}(275 \mathrm{MPa}), 60 \mathrm{ksi}(413 \mathrm{MPa})$, and $120 \mathrm{ksi}(826 \mathrm{MPa})$ for specimens made with U.S. Grade 40 (Grade $280 \mathrm{MPa}$ ), U.S. Grade 60 (Grade $420 \mathrm{MPa}$ ), and U.S. Grade 120 (Grade $820 \mathrm{MPa}$ ) reinforcement, respectively. The tensile properties of UHPC used are shown in Table 2. Regarding the Crane data, ${ }^{25}$ the tensile material properties of UHPC were not reported. As such, a tensile strength at localization value of $1.5 \mathrm{ksi}(10.3 \mathrm{MPa})$ was assumed, and the stress in the reinforcement was assumed to reach yielding, $f_{y}$ $=60 \mathrm{ksi}(413 \mathrm{MPa})$. Furthermore, for both sets of data, the material reduction factor for UHPC was taken as 0.85 , as recommended in Table 3. As shown in Fig. 11, the proposed capacity model delivers conservative results when applied to predict the behavior of the test specimens. That is, all data shown either lays on or above the line of unity. 


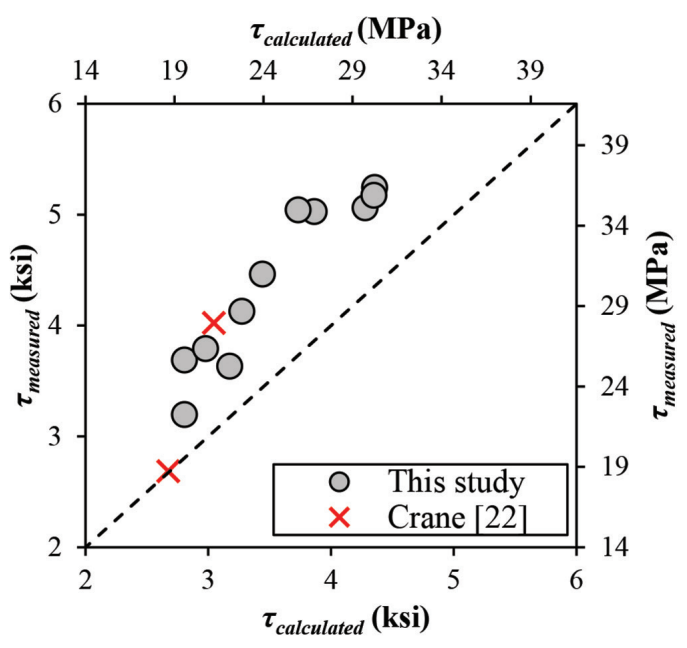

Fig. 11-Comparison of measured shear stress capacity, $\tau_{\text {measured, }}$ to shear stress capacity calculated using proposed model, $\tau_{\text {calculated; }}$ nominal yield strengths of steel and $\gamma=0.85$ used for $\tau_{\text {calculated. }}$.

\section{SUMMARY AND CONCLUSIONS}

This paper investigated the interface shear performance of monolithic UHPC with and without reinforcing steel crossing the intended shear plane. Eleven relatively largescale, single-shear tests were completed. Test results were used to make general observations related to load deformation behavior, failure modes, ultimate and post-peak shear stress capacity, and strains in UHPC and reinforcing steel. The data demonstrated that the peak interface shear stress is dependent on the tensile properties of both reinforcing steel and UHPC. Furthermore, it was observed that there is compatibility between UHPC and the steel reinforcement crossing the interface. The observed compatibility, along with the other observations made from test data, were used to develop an interface shear capacity model for UHPC. The primary difference between the interface shear capacity model for UHPC and those used for conventional concrete is that the tensile properties of the cement-based material are included in the formulation. The model is also compatible with different grades of reinforcing steel. The following conclusions can be made based on the work presented herein:

- The interface shear capacity of monolithic UHPC (with $2.0 \%$ steel fiber reinforcement in this case), exhibiting a localization stress of $1.70 \mathrm{ksi}(11.7 \mathrm{MPa})$ at a mature age and without supplemental interface steel reinforcement, is likely greater than $3 \mathrm{ksi}(20 \mathrm{MPa})$.

- $\quad$ First cracking of UHPC subjected to interface shear appears to be independent of whether supplemental steel reinforcement is present. Furthermore, the apparent first cracking seems to occur between applied shear stresses of 1 and $2 \mathrm{ksi}$ (6.9 and $13.8 \mathrm{MPa}$ ).

- Like conventional concrete, the interface shear capacity of UHPC can be increased by providing supplemental steel reinforcement across the interface. Moreover, the increase in capacity is proportional to the clamping force provided by steel. The post-peak or residual shear capacity of the interface is also proportional to the quantity and properties of the supplemental reinforcement provided.
- $\quad$ The proposed interface shear stress capacity model is based on rational principles, has a general form similar to interface shear stress capacity models currently used for conventional concrete, and includes variables that can be determined using nominal material properties or measured properties of UHPC and reinforcing steel. Lastly, the proposed model conservatively predicts test results considered in this study.

\section{AUTHOR BIOS}

ACI member Scott Muzenski is a Research Engineer for Genex Systems, LLC at the Federal Highway Administration Turner-Fairbank Highway Research Center (FHWA TFHRC). He received his BS, MS, and PhD from the University of Wisconsin-Milwaukee, Milwaukee, WI. He is a member of ACI Committee 241, Nanotechnology of Concrete. His research interests include structural behavior of ultra-high-performance concrete (UHPC), advanced cement-based materials, and nanotechnology in civil engineering.

ACI member Zachary B. Haber is a Research Structural Engineer with the FHWA at the TFHRC. He received his BS and MS in civil engineering from the University of Central Florida, Orlando, FL, and his PhD in civil engineering from the University of Nevada, Reno, Reno, $N V$. His research interests include large-scale testing, advanced materials in civil engineering, and bridge engineering.

ACI member Benjamin Graybeal is the team leader for bridge engineering research with FHWA at TFHRC. He received his BS and MS in civil engineering from Lehigh University, Bethlehem, $P A$, and his PhD from the University of Maryland, College Park, MD. He is Chair of ACI Committee 239, Ultra-High-Performance Concrete. His technical portfolio includes bridge engineering, advanced infrastructure materials, and forensic structural engineering.

\section{ACKNOWLEDGMENTS}

The research presented in this article was funded by the U.S. FHWA. The publication of this article does not necessarily indicate approval or endorsement of the findings, opinions, conclusions, or recommendations, either inferred or specifically expressed herein, by the FHWA or the U.S. government. The authors would like to extend a special thanks to K. Zmetra and the members of the FHWA Structural Concrete Research Program for their contributions to this research.

\section{REFERENCES}

1. El-Helou, R.; Haber, Z. B.; and Graybeal, B., Mechanical Behavior and Design Properties of Ultra-High Performance Concrete, ACI Materials Journal, Accepted 2021.

2. Haber, Z. B.; De la Varga, I.; Graybeal, B. A.; Nakashoji, B.; and El-Helou, R., "Properties and Behavior of UHPC-Class Materials (FHWA-HRT-18-036)," U.S. Department of Transportation, Federal Highway Administration, McLean, VA, 2018.

3. Graybeal, B. A., and Russel, H. G., "Ultra-High Performance Concrete: A State-of-the-Art Report for the Bridge Community (FHWA-HRT-13-060),' U.S. Department of Transportation, Federal Highway Administration, McLean, VA, June 2013, p. 176.

4. El-Helou, R. G., and Graybeal, B. A., "The Ultra Girder: A Design Concept for a 300-Foot Single Span Prestressed Ultra-High Performance Concrete Bridge Girder," International Interactive Symposium on Ultra-High-Performance Concrete, V. 2, No. 1, 2019. pp. 1-9.

5. Wipf, T.; Phares, B.; Sritharan, S.; Degen, B. E.; and Giesmann, M. T., "Design and Evaluation of a Single-Span Bridge Using Ultra-High Performance Concrete (IHRB Project TR-529)," Federal Highway Admiration, Iowa Highway Research Board, Ames, IA, Sept. 2009, p. 148.

6. Haber, Z. B.; Graybeal, B. A.; and Nakashoji, B., "Ultimate Behavior of Deck-to-Girder Composite Connection Details Using UHPC," Journal of Bridge Engineering, ASCE, V. 25, No. 7, 2020, p. 04020038 doi: 10.1061/ (ASCE)BE.1943-5592.0001574

7. Birkeland, P. W., and Birkeland, H. W., "Connections in Precast Concrete Construction," ACI Journal Proceedings, V. 63, No. 3, Mar. 1966, pp. 345-368.

8. Hanson, W., "Precast-Prestressed Concrete Bridges 2: Horizontal Shear Connections," Portland Cement Association, Research and Development Laboratories, Skokie, IL, 1960.

9. Anderson, A. R., "Composite Designs in Precast and Cast-in-Place Concrete," Progressive Architecture, V. 41, No. 9, 1960, pp. 172-179. 
10. ACI Committee 318, "Building Code Requirements for Structural Concrete (ACI 318-19) and Commentary (ACI 318R-19)," American Concrete Institute, Farmington Hills, MI, 2019, 624 pp.

11. Mattock, A. H., and Hawkins, N. M., "Shear Transfer in Reinforced Concrete-Recent Research," PCI Journal, V. 17, No. 2, 1972, pp. 55-75. doi: 10.15554/pcij.03011972.55.75

12. Loov, R. E., "Design of Precast Connections," Seminar, Compa International, Singapore, 1978.

13. Loov, R. E., and Patnaik, A. K., "Horizontal Shear Strength of Composite Concrete Beams with a Rough Interface," PCI Journal, V. 39, No. 1, 1994, pp. 48-69. doi: 10.15554/pcij.01011994.48.69

14. Mattock, A. H., "Shear Friction and High-Strength Concrete," ACI Structural Journal, V. 98, No. 1, Jan.-Feb. 2001, pp. 50-59.

15. Kahn, L. F., and Mitchell, A. D., "Shear Friction Tests with HighStrength Concrete," ACI Structural Journal, V. 99, No. 1, Jan.-Feb. 2002, pp. 98-103.

16. Hofbeck, J. A.; Ibrahim, I. O.; and Mattock, A. H., "Shear Transfer in Reinforced Concrete," ACI Journal Proceedings, V. 66, No. 2, Feb. 1969, pp. 119-128.

17. Tsoukantas, S. G., and Tassios, T. P., "Shear Resistance of Connections between Reinforced Concrete Linear Precast Elements," ACI Structural Journal, V. 86, No. 3, May-June 1989, pp. 242-249.

18. Randl, N., "Investigations on Transfer of Forces between Old and New Concrete at Different Joint Roughness," PhD thesis, University of Innsbruck, Innsbruck, Austria, 1997.

19. Santos, P. M. D., and Júlio, E. N. B. S., "Interface Shear Transfer on Composite Concrete Members," ACI Structural Journal, V. 111, No. 1, Jan.-Feb. 2014, pp. 113-121.

20. Federation International du Béton, (fib), "Model Code 2010: Final Draft," Bulletin Nos. 65/66, International Federation for Structural Concrete (fib), Lausanne, Switzerland, 2012.

21. American Association of State Highway and Transportation Officials, "AASHTO LRFD Bridge Design Specifications," ninth edition, AASHTO, Washington, DC, 2020.

22. European Committee for Standardization, "Eurocode 2: Design of Concrete Structures-Part 1-1: General Rules and Rules for Buildings (EN 1992-1-1)," CEN, Brussels, Belgium, 2004.

23. Canadian Standards Association, "Canadian Highway Bridge Design Code (CSA S6:19)," CSA Group, Rexdale, ON, Canada, 2019.

24. Association Française de Normalisation, "National Addition to Eurocode 2-Design of Concrete Structures: Specific Rules for Ultra-High Performance Fibre-Reinforced Concrete (UHPFRC) (NF P18-710:201604-16)," Beuth, La Plaine Saint-Denis, France, 2016.

25. Crane, C. K., "Shear and Shear Friction of Ultra-High Performance Concrete Bridge Girders," PhD dissertation, Georgia Institute of Technology, Atlanta, GA, 2010.

26. Jang, H. O.; Lee, H. S.; Cho, K.; and Kim, J., "Experimental Study on Shear Performance of Plain Construction Joints Integrated with UltraHigh Performance Concrete (UHPC)," Construction and Building Materials, V. 152, Oct. 2017, pp. 16-23. doi: 10.1016/j.conbuildmat.2017.06.156

27. Wu, P.; Wu, C.; Liu, Z.; and Hao, H., "Investigation of Shear Performance of UHPC by Direct Shear Tests," Engineering Structures, V. 183, Mar. 2019, pp. 780-790. doi: 10.1016/j.engstruct.2019.01.055

28. Semendary, A. A., and Svecova, D., "Interfacial Parameters for Bridge Connections at High-Strength Concrete-Ultrahigh-Performance Concrete Interface," Journal of Materials in Civil Engineering, ASCE, V. 32, No. 4, 2020, pp. 1-14. doi: 10.1061/(ASCE)MT.1943-5533.0003107

29. Kim, Y. J.; Chin, W. J.; and Jeon, S. J., "Interface Shear Strength at Joints of Ultra-High Performance Concrete Structures," International Journal of Concrete Structures and Materials, V. 12, No. 1, 2018, p. 59 doi: 10.1186/s40069-018-0298-8
30. Liu, T.; Wang, Z.; Guo, J.; and Wang, J., "Shear Strength of Dry Joints in Precast UHPC Segmental Bridges: Experimental and Theoretical Research," Journal of Bridge Engineering, ASCE, V. 24, No. 1, 2019 p. 04018100 doi: 10.1061/(ASCE)BE.1943-5592.0001323

31. Zhang, Y.; Zhu, P.; Wang, X.; and Wu, J., "Shear Properties of the Interface between Ultra-High Performance Concrete and Normal Strength Concrete," Construction and Building Materials, V. 248, July 2020 , p. 118455 doi: 10.1016/j.conbuildmat.2020.118455

32. Jiang, H.; Shao, T.; Fang, Z.; Xiao, J.; and Hu, Z., "Shear-Friction Behavior of Grooved Construction Joints between a Precast UHPC Girder and a Cast-in-Place Concrete Slab," Engineering Structures, V. 228, Feb. 2021, p. 111610 doi: 10.1016/j.engstruct.2020.111610

33. Semendary, A. A., and Svecova, D., "Bond Characterization and Interfacial Coefficients at Precast UHPC and Cast-in-Place UHPC Interface," Journal of Materials in Civil Engineering, ASCE, V. 33, No. 7, 2021, p. 4021143 doi: 10.1061/(ASCE)MT.1943-5533.0003755

34. Valikhani, A.; Jahromi, A. J.; Mantawy, I. M.; and Azizinamini, A., "Effect of Mechanical Connectors on Interface Shear Strength between Concrete Substrates and UHPC: Experimental and Numerical Studies and Proposed Design Equation," Construction and Building Materials, V. 267, Nov. 2020, p. 120587

35. Zhang, Y.; Zhang, C.; Zhu, Y.; Cao, J.; and Shao, X., "An Experimental Study: Various Influence Factors Affecting Interfacial Shear Performance of UHPC-NSC," Construction and Building Materials, V. 236, Mar. 2020, p. 117480 doi: 10.1016/j.conbuildmat.2019.117480

36. Semendary, A. A.; Hamid, W. K.; Steinberg, E. P.; and Khoury, I., "Shear Friction Performance between High Strength Concrete (HSC) and Ultra High Performance Concrete (UHPC) for Bridge Connection Applications," Engineering Structures, V. 205, Feb. 2020, p. 110122 doi: 10.1016/j. engstruct.2019.110122

37. Yuan, J., and Graybeal, B., "Bond of Reinforcement in Ultra-High-Performance Concrete," ACI Structural Journal, V. 112, No. 6, Nov.-Dec. 2015, pp. 851-860. doi: 10.14359/51687912

38. Wille, K., and Parra-Montesinos, G. J., "Effect of Beam Size, Casting Method, and Support Conditions on Flexural Behavior of Ultra-High-Performance Fiber-Reinforced Concrete," ACI Materials Journal, V. 109, No. 3, May-June 2012, p. 379

39. Duque, L. F. M., and Graybeal, B., "Fiber Orientation Distribution and Tensile Mechanical Response in UHPFRC," Materials and Structures, V. 50, No. 1, 2017, p. 55 doi: 10.1617/s11527-016-0914-5

40. ASTM C1856/C1856M-17, "Standard Practice for Fabricating and Testing Specimens of Ultra-High Performance Concrete," ASTM International, West Conshohocken, PA, 2017.

41. Graybeal, F., and Baby, B., "Tension Testing of Ultra-High Performance Concrete (FHWA-HRT-17-053)," U.S. Department of Transportation, Office of Infrastructure Research \& Development Federal Highway Administration, McLean, VA, 2019.

42. Graybeal, B. A., and Baby, F., "Development of Direct Tension Test Method for Ultra-High-Performance Fiber-Reinforced Concrete," $A C I$ Materials Journal, V. 110, No. 2, Mar.-Apr. 2013, pp. 177-186.

43. ASTM A615/A615M-20, "Standard Specification for Deformed and Plain Carbon-Steel Bars for Concrete Reinforcement," ASTM International, West Conshohocken, PA, 2020.

44. ASTM A1035/A1035M-19, "Standard Specification for Deformed and Plain, Low-Carbon, Chromium, Steel Bars for Concrete Reinforcement," ASTM International, West Conshohocken, PA, 2019.

45. Kahn, L. F., and Crane, C. K., "Shear Friction \& Interface Shear of Ultra High Performance Concrete (GDOT Research Project No. 07-05 Task Order No. 02-37)," Georgia Institute of Technology, Atlanta, GA, 2010. 


\section{APPENDIX I-NOTATIONS}

2 The following symbols are used in the paper:

$3 A_{c v}=$ Nominal area of interface

$4 A_{c v, m}=$ Measured area of interface

$5 A_{s v} \quad=$ Area of steel reinforcement crossing the shear interface

$6 \quad c=y-i n t e r c e p t$ coefficient, cohesion coefficient

$7 \quad E_{s} \quad=$ Elastic modulus of reinforcing steel

$8 E_{U H P C}=$ Elastic modulus of UHPC

$9 \quad f^{\prime}{ }_{c} \quad=$ Compressive strength

$10 f_{s} \quad=$ Stress in reinforcing steel

$11 f_{\text {s, peak }}=$ Stress in reinforcement at the time of peak applied load

$12 f_{t, c r}=$ Apparent first tension cracking of UHPC

$13 f_{t, l o c}=$ Localization stress of UHPC

$14 f_{y} \quad=$ Specified yield stress of interface reinforcement

$15 f_{\text {y,measured }}=$ Measured yield stress of interface reinforcement

$16 K=$ Limiting shear stress capacity

$17 \quad P_{c} \quad=$ Permanent net compressive force

$18 V_{n} \quad=$ Nominal interface shear capacity

$19 \varepsilon_{n} \quad=$ Strain normal to the interface

$20 \varepsilon t, l o c=$ Localization strain when the stress is continuously decreasing with increasing strain

$21 \quad \varepsilon_{y} \quad=$ Yield strain of reinforcing steel

$22 \quad \varepsilon y, m=$ Measured yield strain of reinforcing steel

$23 \gamma \quad=$ Material reduction factor for UHPC in tension 


$$
\begin{array}{llll}
1 & \phi & =\text { Strength reduction factor } \\
2 & \rho_{v} & =\text { Interface reinforcement ratio }=\frac{A_{s v}}{A_{c v}} \\
3 & \tau & =\text { Interface shear stress } \\
4 & \tau_{\text {calculated }} & =\text { Calculated interface shear stress capacity } \\
5 & \tau_{\text {measured }} & =\text { Measured interface shear stress capacity } \\
6 & \mu & =\text { Friction coefficient }
\end{array}
$$

\section{APPENDIX II-EXPERIMENTAL INVESTIGATION}

\section{Specimen Fabrication}

10 Fig. A-1(a) shows a photo of the forms for a typical specimen ready for placement of UHPC.

11 UHPC was mixed on site in the laboratory using a vertical shaft high shear mixer with

12 counter-current mixing action. Each specimen was cast from a separate batch of UHPC, with the

13 exception of the specimens cast with U.S. Grade 40 (Grade $280 \mathrm{MPa}$ ) interface reinforcement,

14 which were all cast from the same batch of material; this was primarily due to the volume of each

15 batch. After mixing each batch, the static flow of UHPC was measured according to ASTM

$16 \mathrm{C} 1856^{40}$. The measured static flow for all batches was between $8.5 \mathrm{in} .(216 \mathrm{~mm})$ and $10.0 \mathrm{in}$. $(254$

$17 \mathrm{~mm}$ ). Specimens were cast monolithically by pouring a continuous stream of fresh UHPC into the

18 lower knee of the specimen (Fig. A-1(b)) and letting it freely flow across the interface region (Fig.

19 A-1(c)) until the mold was full. Compression testing cylinders, measuring 3 in. (76 mm) in

20 diameter by 6 in. $(152 \mathrm{~mm})$ long, were also fabricated with each batch of UHPC. Cylinders were

21 cast and tested according to ASTM C1856 $6^{40}$. Prisms for direct tension testing were also cast with

22 each batch of UHPC. The prisms were 2 in. $(50.8 \mathrm{~mm})$ by 2 in. $(50.8 \mathrm{~mm})$ by $17 \mathrm{in.}(431.8 \mathrm{~mm})$

23 and were tested based on the method described by Graybeal and Baby ${ }^{41}$. The cylinders and prisms 
1 were stored in the laboratory near the interface shear specimens until testing.

\section{UHPC Tensile Properties}

3 The tensile properties of the UHPC that composed each interface shear specimen are listed in

4 Table A-1.

5 Steel Reinforcement Properties

6 The average measured tensile properties of the steel reinforcement used for interface

7 reinforcement are listed in Table A-2. Fig. A-2 depicts a representative set of tensile stress-strain

8 curves for the steel reinforcement used for the interface.

10 APPENDIX III-EXPERIMENTAL RESULTS

\section{$11 \quad$ Failure Modes}

12 Photographs of select specimens prior to and after testing can be observed in Fig. A-3. Fig. A-

13 3(a)-Fig. A-3(c) depict the pre and postfailure condition of specimens that did not employ interface

14 reinforcement; here, the interface is denoted by a vertical, dashed, black line.

15 Fig. A-3(d)-Fig. A-3(i) depict the pre and postfailure condition of specimens with interface

16 reinforcement; here, horizontal, solid, black lines were marked on the specimens to represent the

17 location of the interface reinforcement.

\section{Postpeak Shear Stress Capacity}

19 The postpeak shear stress capacity of each specimen after rupture of UHPC is shown in Fig.

20 A-4 as a function of the clamping pressure. Here, the clamping pressure was calculated as the

21 product of the interface reinforcement ratio and the yield stress of steel. The representation displays

22 a linear relationship, as it is acknowledged that the postpeak shear resistance after UHPC

23 localization and fiber pullout is entirely provided by the interface shear reinforcing bars. 


\section{$1 \quad$ Measured Strains}

2 Fig. A-5 depicts the relationship between the applied shear stress and $\varepsilon_{n}$ for a representative 3 set of specimens. Here, the curves have been truncated at the point where peak shear load occurs

4 for a given specimen. The peak shear load occurs shortly before localization of the UHPC.

5 Specimens all exhibited similar $\tau$ - $\varepsilon_{n}$ relationships. That is, each specimen exhibited an

6 approximately linear ascending branch of the $\tau-\varepsilon n$ curve, which quickly began to soften soon after

7 approximately $\tau=1.0 \mathrm{ksi}(6.9 \mathrm{MPa})$. Despite having different peak shear stresses, the normal strain

8 in UHPC at peak load was relatively consistent amongst the specimens and was in the range of 90.0025 to 0.0040 . 


\section{TABLES AND FIGURES}

2 List of Tables

3 Table A-1 - Measured UHPC tensile material properties of test specimens

4 Table A-2 - Average measured tensile properties of steel reinforcement

6 List of Figures

$7 \quad$ Fig. A-1 - Specimen placement.

8 Fig. A-2 - Representative tensile stress-strain behavior of steel reinforcement.

9 Fig. A-3 - Representative images of specimens prior to (a, d, g), after testing (b, e, h), and close

10 up of localized UHPC (c, f, i).

11 Fig. A-4 - Postpeak capacity versus clamping pressure of tested specimens.

12 Fig. A-5 - Shear stress versus UHPC strain normal to interface of select specimens. 
Table A-1 - Measured UHPC tensile material properties of test specimens

\begin{tabular}{lllll}
\hline $\begin{array}{l}\text { Batch } \\
\text { ID }\end{array}$ & Specimen IDs ${ }^{\mathbf{a}}$ & $\begin{array}{l}\text { 1st crack stress, } \boldsymbol{f}_{\boldsymbol{t}, \boldsymbol{c r}} \mathbf{b} \\
\text { Mean } \pm \text { SD } \\
\text { ksi (MPa) }\end{array}$ & $\begin{array}{l}\text { Localization stress, } \\
\boldsymbol{f}_{\text {,loc }} \mathbf{b} \\
\mathbf{M e a n} \pm \text { SD } \\
\mathbf{k s i}(\mathbf{M P a})\end{array}$ & $\begin{array}{l}\text { Localization } \\
\text { strain } \\
\text { Mean } \pm \text { SD }\end{array}$ \\
\hline 1 & BL-0.0A, BL-0.0B & $1.66 \pm 0.11(11.4 \pm 0.76)$ & $1.66 \pm 0.11(11.4 \pm 0.76)$ & $0.00531 \pm 0.00098$ \\
2 & N-0.24, N-0.73, N-0.98 & $1.75 \pm 0.13(12.1 \pm 0.90)$ & $1.75 \pm 0.13(12.1 \pm 0.90)$ & $0.00490 \pm 0.00190$ \\
3 & N-1.38 & $1.43 \pm 0.12(9.6 \pm 0.83)$ & $1.43 \pm 0.12(9.6 \pm 0.83)$ & $0.00410 \pm 0.00042$ \\
4 & N-2.07 & $1.44 \pm 0.10(9.9 \pm 0.69)$ & $1.44 \pm 0.10(9.9 \pm 0.69)$ & $0.00295 \pm 0.00076$ \\
5 & N-2.76 & $1.53 \pm 0.06(10.5 \pm 0.41)$ & $1.53 \pm 0.06(10.5 \pm 0.41)$ & $0.00245 \pm 0.00007$ \\
6 & H-1.38 & $1.17 \pm 0.10(8.1 \pm 0.69)$ & $1.17 \pm 0.10(8.1 \pm 0.69)$ & $0.00335 \pm 0.00021$ \\
7 & H-2.07 & $1.29 \pm 0.08(8.9 \pm 0.55)$ & $1.29 \pm 0.08(8.9 \pm 0.55)$ & $0.00297 \pm 0.00051$ \\
8 & H-2.76 & $1.24 \pm 0.05(8.5 \pm 0.34)$ & $1.24 \pm 0.05(8.5 \pm 0.34)$ & $0.00240 \pm 0.00017$ \\
\hline
\end{tabular}

Notes:

${ }^{a}$ Some specimens were cast from the same batch.

${ }^{\mathrm{b}} 1^{\text {st }}$ crack stress and localization stress were determined based on the UHPC material model discussed by ElHelou et al. ${ }^{1}$.

$\mathrm{SD}=$ Standard Deviation

3 Table A-2 - Average measured tensile properties of steel reinforcement

\begin{tabular}{ccccc}
\hline $\begin{array}{c}\text { Grade } \\
\text { US } \\
\text { (Metric) }\end{array}$ & $\begin{array}{c}\text { Bar Size } \\
\text { US } \\
\text { (Metric) }\end{array}$ & $\begin{array}{c}\text { Yield Stress } \\
\text { Mean } \pm \text { SD } \\
\text { ksi (MPa) }\end{array}$ & $\begin{array}{c}\text { Strain at onset of } \\
\text { strain hardening } \\
\text { Mean } \pm \text { SD }\end{array}$ & $\begin{array}{c}\text { Ultimate Tensile } \\
\text { Stress } \\
\text { Mean } \pm \text { SD } \\
\text { ksi (MPa) }\end{array}$ \\
\hline $40(280)$ & $\# 3(\varnothing 10)$ & $54.6 \pm 0.50(376 \pm 3.45)$ & $0.0212 \pm 0.00075$ & $78.5 \pm 0.21(541 \pm 1.45)$ \\
$60(420)$ & $\# 5(\varnothing 16)$ & $82 \pm 0.16(565 \pm 1.10)$ & $0.0158 \pm 0.00065$ & $103.9 \pm 0.37(716 \pm 2.55)$ \\
$120(820)$ & $\# 5(\varnothing 16)$ & $128 \pm 3.16(882 \pm 20.68)$ & na & $161.5 \pm 0.75(1,113 \pm 5.17)$ \\
\hline
\end{tabular}

Notes:

$\mathrm{na}=$ not applicable, stress-strain curve did not have a well-defined yield plateau.

$\mathrm{SD}=$ Standard Deviation

Specimen details. 


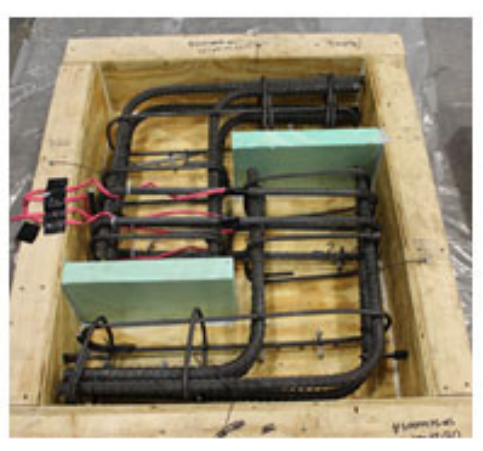

(a) Specimen ready for casting

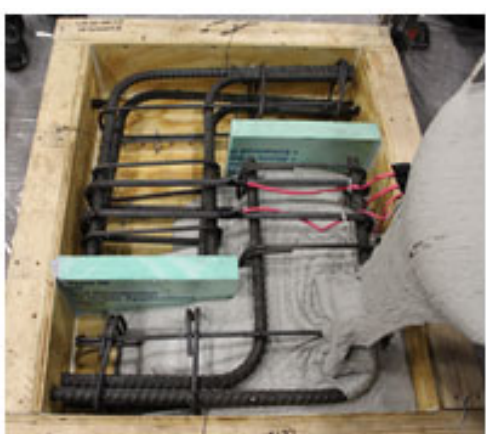

(b) UHPC placement

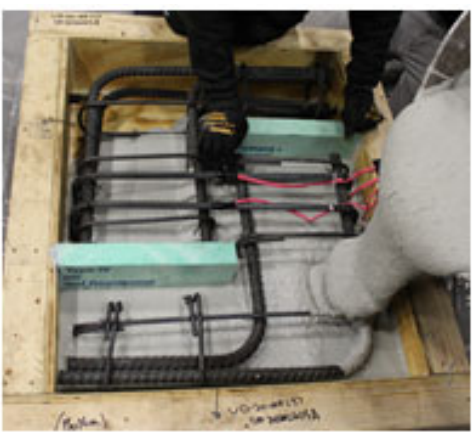

(c) Flow of UHPC

Fig. A-1 - Specimen placement.

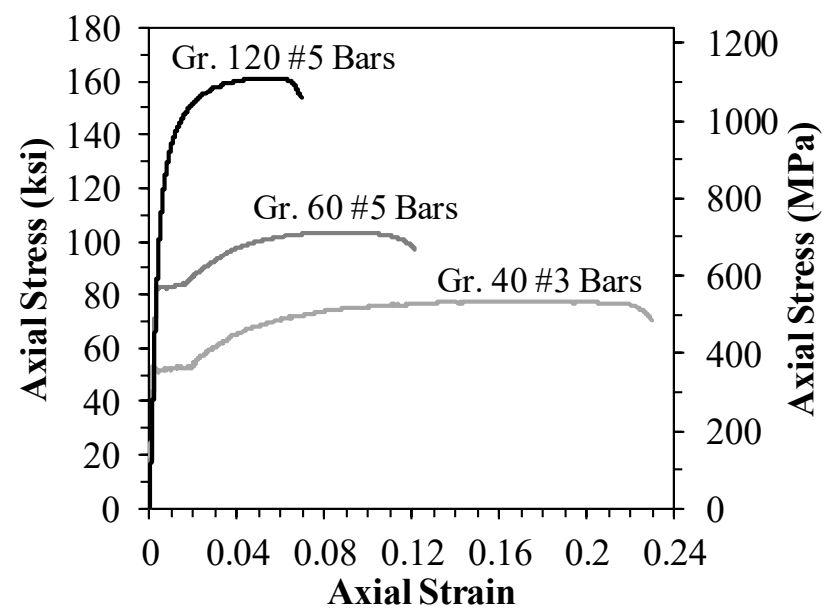

Fig. A-2 - Representative tensile stress-strain behavior of steel reinforcement. 


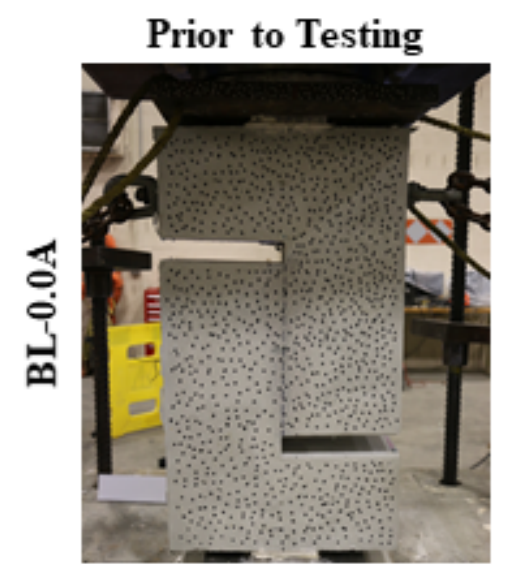

(a)

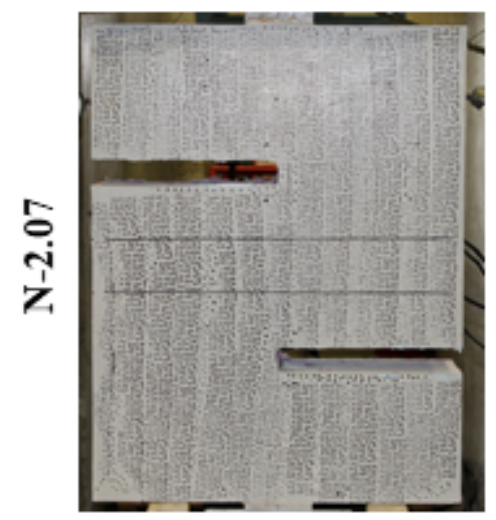

(d)

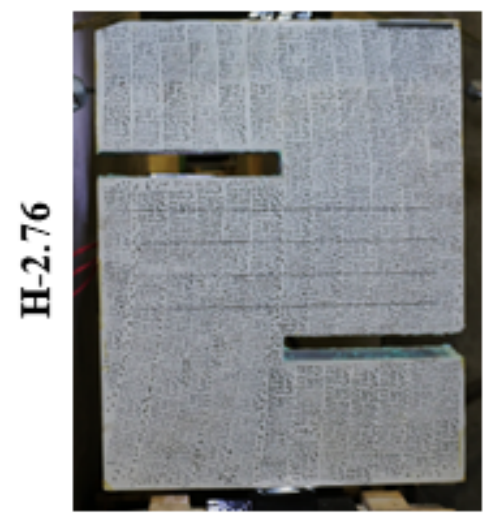

(g)

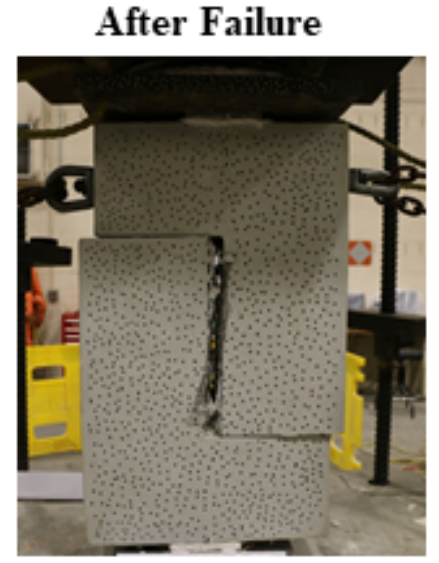

(b)

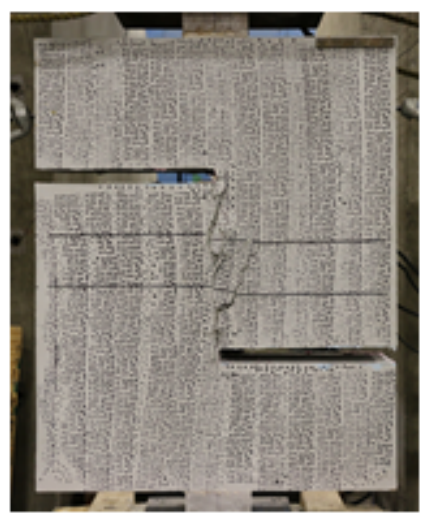

(e)

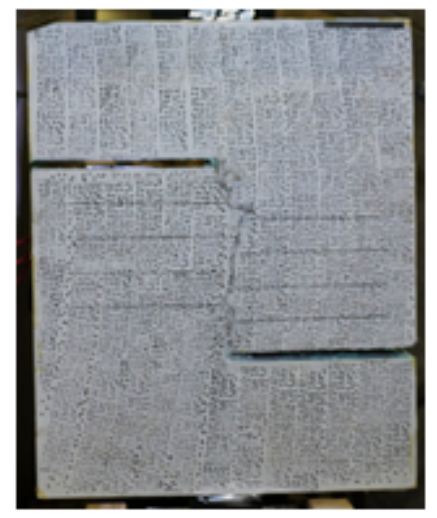

(h)
Close-up of Ruptured UHPC

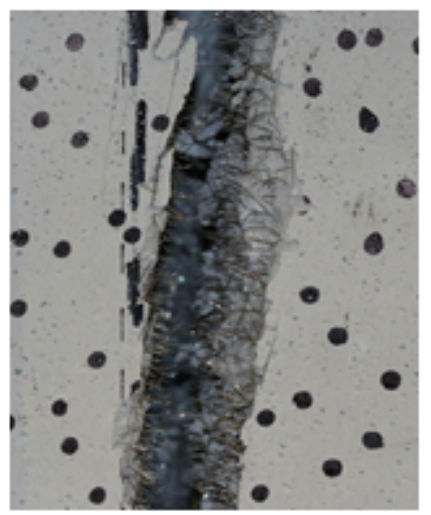

(c)

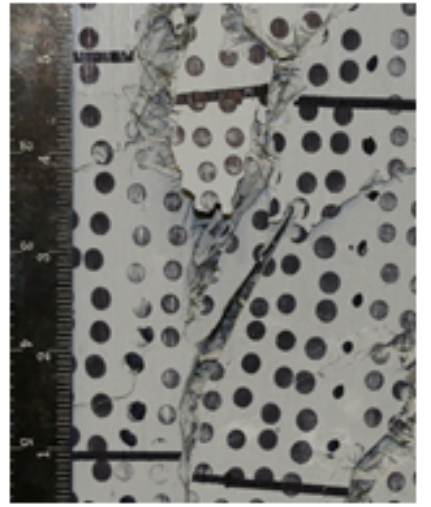

(f)

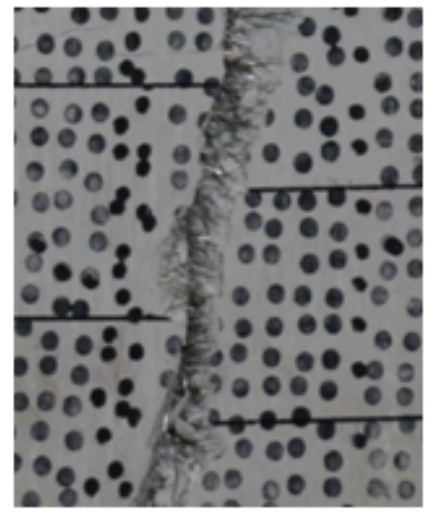

(1)

2 Fig. A-3 - Representative images of specimens prior to (a, d, g), after testing (b, e, h), and close 3 up of localized UHPC (c, f, i). 


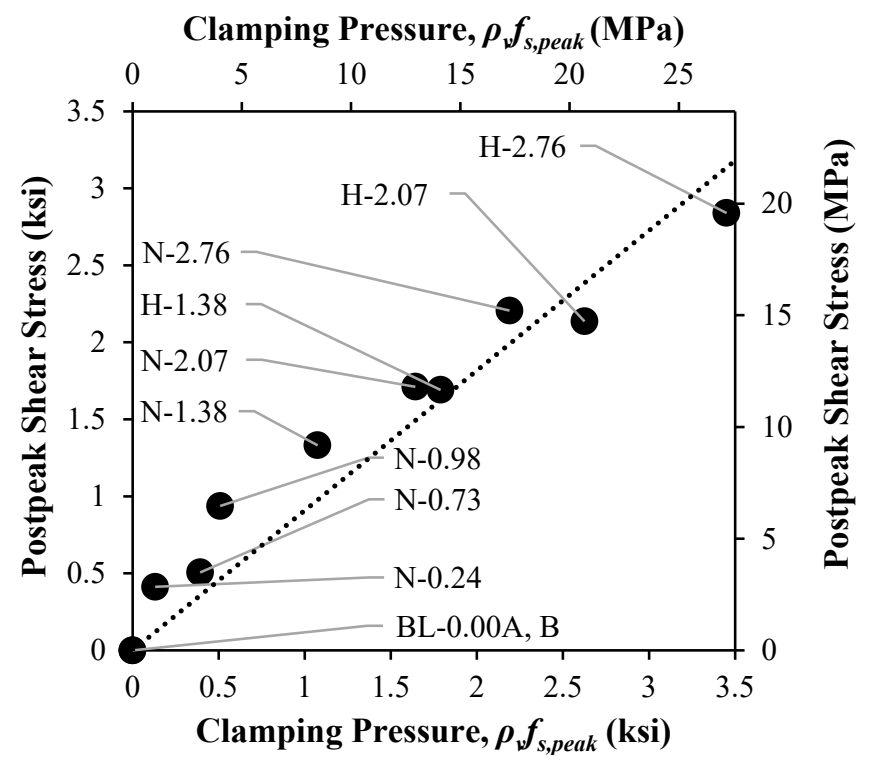

Fig. A-4 - Postpeak capacity versus clamping pressure of tested specimens.

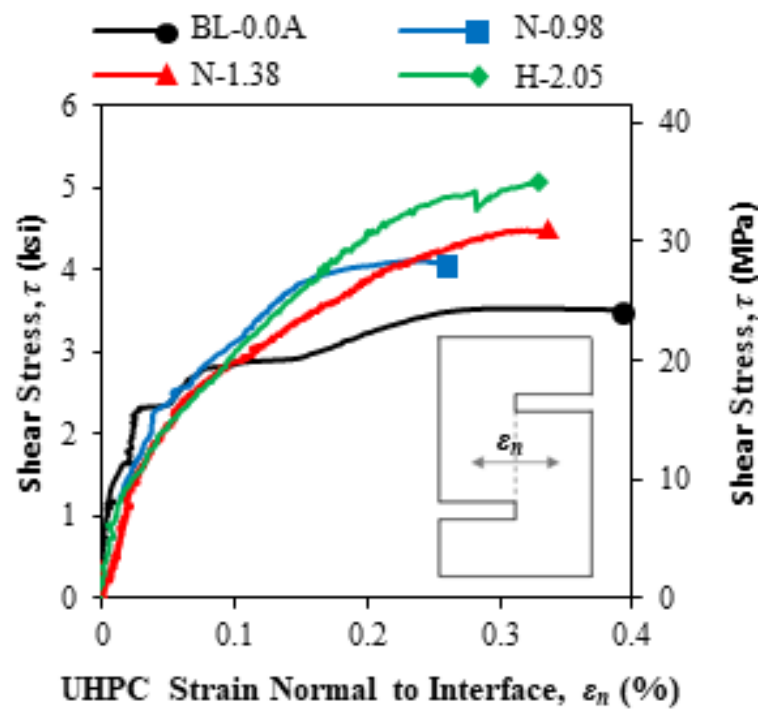

Fig. A-5 - Shear stress versus UHPC strain normal to interface of select specimens. 